\title{
A multi-period equilibrium pricing model of weather derivatives
}

\author{
Yongheon Lee • Shmuel S. Oren
}

Received: 8 June 2009 / Accepted: 7 December 2009 / Published online: 12 January 2010

(C) The Author(s) 2010. This article is published with open access at Springerlink.com

\begin{abstract}
The prevalence of commercial activities whose profit and cost are correlated with weather risk makes weather derivatives valuable financial instruments that enable hedging of price or volumetric (quantity) risk in many industries. This paper proposes a multi-period equilibrium pricing model for weather derivative. In our stylized economy representative agents of weather-sensitive industries optimizes their hedging portfolios that drive the supply and demand for weather derivative which are dynamically determined based on a utility indifference pricing framework. At equilibrium the weather derivative market will be cleared and their market price can be obtained. Numerical examples illustrate the equilibrium prices and optimal choices for the weather derivative as function of the correlation between weather indices and demand for the underlying commodity. We also demonstrate the benefit of multiple trading opportunities which allows rebalancing of the hedging portfolio prior to the commodity delivery date, as compared to a single shot framework.
\end{abstract}

\section{Introduction}

Weather derivatives are contingent claims whose payoff depends on the value of an underlying weather index such as degree days over the contract periods, precipitation, snowfall, and frost days. Many weather-sensitive industries such as energy, insurance, agriculture, and leisure confront two types of risk; price risk and volumetric (or quantity) risk, which are both correlated with weather. Existing commodity derivatives cannot be used to fully hedge price and volumetric risks because

Y. Lee $\cdot$ S.S. Oren $(\bowtie)$

Department of Industrial Engineering and Operations Research, University of California, Berkeley,

CA, USA

e-mail: oren@ieor.berkeley.edu

Y. Lee

e-mail: yhlee@ieor.berkeley.edu 
the two risks are not perfectly correlated and volume instruments are not traded. Therefore, weather-sensitive industries may wish to diversify their portfolios by introducing financial instruments driven by weather indices to mitigate risk which cannot be covered by commodity derivatives. One of the main buyers of weather derivatives is the energy industry because it needs to stabilize profits as the market becomes deregulated and more competitive and because temperature is the most significant factor which affects price and demand of power and natural gas (see [21]). Weather derivatives were initially introduced by energy companies such as Enron, Koch Industries, Southern Energy, Aquila and Castlebridge Weather Markets in the over-the-counter (OTC) markets of the US in 1996. In order to meet rapidly growing demand and increase liquidity and accessibility, the Chicago Mercantile Exchange (CME) launched the first electronic market place for standardized weather derivatives in 1999. In 200718 US cities' weekly, monthly, and seasonal weather derivatives, 6 European, 2 Asia-Pacific, 6 Canadian cities' monthly and seasonal weather derivatives are being traded at CME. Also Hurricane weeklies were newly listed in 2007. In spite of the rapid market growth at CME, over-thecounter (OTC) markets are still important since weather indices are highly locationdependent.

Despite the advantages and increased use of weather derivatives, there are no effective pricing models for these instruments because the underlying weather index is not a tradable commodity or equity share and the market is incomplete. Therefore, classical arguments based on the existence of the unique risk-neutral probability measure or a perfect replication of the weather derivatives payoff cannot be applied (see [5, 15, 23]). Jouini [18] reviews three approaches to derivative pricing in complete and incomplete markets; the arbitrage approach through the existence of a risk-neutral density, the utility approach through a utility maximization, and the equilibrium approach through a market clearing condition. Staum [29] surveys pricing methodologies of derivative securities in incomplete markets such as no-arbitrage pricing and indifference pricing as a special case of good deal bounds detailed in [28], marginal pricing, and risk-neutral pricing. In an incomplete market there exist infinitely many equivalent martingale measures (EMMs) and some criteria are needed to choose a proper EMM, for example, minimum-distance EMM (see [13]), minimization of hedging residual variance (see [27]), and minimal entropy martingale measure (see [12]).

Previous studies on pricing weather derivatives can be classified as actuarial pricing, risk-neutral pricing, indifference pricing, and equilibrium pricing. First, Jewson and Brix [16] discusses statistical issues concerning weather derivative valuation such as parametric and non-parametric distributions for modeling temperature variability, multivariate meteorological forecasting, etc. Platen and West [24] provides a fair pricing model, based on the idea that the growth-optimal portfolio is used as a numeraire and all derivative price processes discounted by the growth optimal portfolio (benchmarked) are martingales under the real world probability measure. Other actuarial methods assuming stochastic daily average temperature have been studied by several researchers (see e.g. [4, 7, 17]). Because of ease of use and their intuitive appeal, the actuarial pricing approach is widely used in insurance industry which usually adds risk loading on top of the premium calculated as the expected value under the 
real world probability measure. However, the actuarial pricing model cannot capture, systematically, the risk-aversion aspect of market participants. Alaton et al. [1] and Yoo [31] propose a risk-neutral pricing model for weather derivatives by inferring an EMM under the assumptions that temperature process follows the OrnsteinUhlenback (O-U) process and the market price of risk is constant. Hamisultane [14] extracts information from the existing weather futures market to find a risk-neutral distribution and the market price of weather risk. Brockett and Wang [6] propose utility indifference pricing in a single-period problem using a mean-variance utility function. They assume that one risky portfolio can represent all risky assets. However, in order to obtain the indifference price it is essential to specify the probability distribution function of the risky portfolio return. Yamada [30] assumes that the risky portfolio return follows a normal distribution to obtain closed form solutions for the indifference valuation of monthly average temperature derivatives. As a special case of indifference pricing marginal pricing is proposed by Davis [11]. Also see [2] for the indifference pricing approach in continuous time. Finally, Cao and Wei [8] suggests a consumption-based equilibrium pricing model by using the Euler equation for valuation of weather derivatives in a discrete time horizon. They assume that in equilibrium both the financial market and the goods market clear so that aggregate consumption equals the dividends generated from the risky stock and then they calculate a Stochastic Discount Factor (SDF) to price weather derivatives. Richards et al. [25] suggested an equilibrium pricing model based on temperature processes following a mean-reverting Brownian motion with discrete jumps and autoregressive conditional heteroscedastic errors. A standard Euler equation from the Lucas general equilibrium valuation model was applied to pricing Cooling Degree Days (CDD) weather options. Chaumont et al. [10] complete the market by constructing a special security which makes climate risk tradable and derive a unique market price of risk at equilibrium, by solving a backward stochastic differential equations.

Unlike other pricing approaches an equilibrium pricing model can explain the market dynamics more realistically because the market price of weather derivatives will settle at the equilibrium price which is between a bid and ask price spread resulting from the various pricing methods. Moreover, in typical weather derivatives markets underwriters have only limited control over prices and the ultimate price of the weather derivatives is determined by supply and demand resulting from hedging activities of market participants exposed to weather risk who are optimizing their hedging portfolios. Therefore, in this paper we propose an equilibrium pricing model in a multi-period setting under an exponential utility preference function. Previously Lee and Oren [20] explored a single-period equilibrium pricing model in a multicommodity setting and as a special case derived closed form expressions for the solutions under the assumption of a mean-variance utility function. Under a similar economic setting as in [20] we will break up the planning horizon of market participants in a discrete manner. In each period agents can rebalance their portfolios by all available information so as to achieve higher expected utility level of terminal wealth. In order to obtain an equilibrium price of weather derivatives we will recursively derive supply and demand functions in each period by combining the indifference pricing method and the expected utility maximization problems of buyers and sellers using a dynamic programming algorithm. An equilibrium price of the weather derivatives in each period can be determined from the derived supply and demand functions. 
The outline of the paper is as follows. In Sect. 2 we first study a single-period indifference pricing problem faced by buyers and sellers and then introduce the multiperiod formulation. Numerical examples are used to illustrate the results and extract insights in Sect. 3. We conclude in Sect. 4.

\section{Model}

\subsection{Assumptions and notation}

In a frictionless economy we consider a multi-period portfolio optimization problem where each representative market participant can rebalance her portfolio at the beginning of each period given the updated information. We assume that there are three types of market participants; weather derivatives buyers with a liquid commodity derivatives market (type $i$ buyers), buyers dealing with a commodity for which there is no liquid commodity derivatives market (type $j$ buyers), and an issuer (underwriter, denoted by $m$ ) of weather derivatives who is a pure financial entity and does not engage in sales of physical commodities or trading of commodity derivatives. All agents can trade on either side, i.e., both types of buyers can engage in short sales whereas the issuer can buy weather derivatives from the market if necessary. We assume that all agents maximize the expected utility of terminal wealth subject to a self-financing constraint. Although Samuelson [26] and Lucas [22] deal with maximizing the sum of the discounted expected utility of consumptions we focus on maximizing the expected utility of terminal wealth because weather-sensitive industries are institutional investors which do not consume any goods and just hedge their risk exposure in peak seasons such as summer or winter in which spot prices, demand, and temperature are more volatile than in spring or fall. Moreover, the buyers' terminal wealth is comprised of three parts; the income from the retail business, the payoff of the commodity portfolio if available, and the payoff of weather derivatives. In our economy the income function has the form of (regulated retail pricewholesale spot price) $\times$ demand, which assumes that each buyer has an obligation to meet random demand at a fixed price either due to a regulatory constraint or competitive pressure. This type of the income function is common in energy industries (e.g. electricity) where the supplier has an obligation to meet variable load at fixed retail prices fixed by regulators or through a service contract for a load slice. ${ }^{1}$ Given the income function, each buyer faces not only spot price risk but also volumetric risk, whereas, spot price, demand, and temperature are all correlated. The demand of the type $i$ and $j$ buyers can be positively or negatively correlated with temperature. The commodity portfolio consists of a risk free bond and commodity derivatives which include forward contracts and European call and put options of all strikes. The underlying asset price of the commodity derivatives is its own spot price. However, if the type $i$ buyers represent electricity distribution companies the underlying asset of

\footnotetext{
${ }^{1}$ Some buyers can have a 'news vendor' type profit function, which means that there may exist shortage cost, inventory cost and salvage values for the leftover stocks. But in this paper, we will not consider a 'news vendor' type profit function for simplicity.
} 
the commodity derivatives will be futures with maturity $N$ because of non-storability of electricity. ${ }^{2}$ Each buyer can trade these financial assets from time 0 to time $N-1$ so as to hedge the two types of risks and maximize expected utility. In addition each buyer is willing to include weather derivatives in her portfolio at or below the indifference price. In other words, each buyer is willing to pay a certain amount for the weather derivative to get utility gains by reducing uncertainty but does not want to be worse off in expected utility terms than without the weather derivative. By applying the indifference pricing to valuation of the weather derivative in the portfolio optimization problem we can determine supply and demand functions for the weather derivative in each period which in turn determine the equilibrium price through a market clearing condition.

We now describe the problems confronted by the buyers and the issuer more specifically. At time 0 the type $i$ buyers with certain initial wealth construct the portfolios consisting of risk-free bonds, commodity derivatives maturing at time 1 , and weather derivative maturing at time $N$. At time 1 the type $i$ buyers have the portfolio values which are realized from the previously constructed portfolios and construct new portfolios given all updated information and so on up to time $N-1$. The type $j$ buyers and the issuer can only trade the risk-free bonds and weather derivatives, but not commodity derivatives which are irrelevant to their risk exposure at time $N$. Indifference pricing and all market participants' expected utility maximization problems enable us to determine the supply and demand functions in each period and as a result we get each period's equilibrium price for the weather derivative in this economy. Therefore, we can formulate the problems of the type $i$ and $j$ buyers and the issuer as separate stochastic dynamic programming problems.

In many financial theories the mean-variance utility function is widely accepted. While in theory it is based on maximizing an exponential utility function over a normally distributed outcome, it is a good approximation under more general utility functions and distributional assumptions (see [19]). However, the mean-variance utility function is hard to deal with in the stochastic dynamic programming setting because of the following property of the variance operator.

$$
\operatorname{var}\left[\operatorname{var}\left(\cdot \mid F_{t}\right) \mid F_{s}\right] \neq \operatorname{var}\left(\cdot \mid F_{s}\right) \quad \forall s<t
$$

where $F_{t}$ is the filtration at time $t$. Therefore, in this paper we assume that all agents are exponential utility maximizers. The exponential utility function is well defined and more tractable in the stochastic dynamic programming setting and in the context of indifference pricing. The exponential utility function has the form of $U(x)=-\frac{1}{a} \exp (-a x)$ where $a$ denotes the risk aversion coefficient and $U(\cdot)$ is smooth, increasing and strictly concave on $R$, and twice continuously differentiable on $R$.

Under the assumptions mentioned in the previous paragraphs we denote a filtered probability space triplet by $(\Omega, \underline{\mathcal{F}}, \mathbb{P})$ in order to formulate the stochastic dynamic programming problems of the buyers and the issuer. The discrete filtration

\footnotetext{
${ }^{2}$ Electricity in different periods must be considered as different assets because once generated, electricity should be consumed immediately.
} 
$\underline{\mathcal{F}}=\left\{\mathcal{F}_{n}\right\}_{n \in\{0,1, \ldots, N\}}$ describes the information structure and $\mathcal{F}_{n}$ represent the information available at time $n$. Let index $k \in\{i, j, m\}$ be the types of the buyers and the issuer. We assume that there are $u$ numbers of the type $i$ buyers, $v$ numbers of the type $j$ buyers, and the representative issuer of weather derivatives denoted by index $m$. The commodity spot (or futures) prices $P_{k, n}$ change their values only at the discrete time $\{0,1, \ldots, N\}$ and are $\mathcal{F}_{n}$-measurable. Demands and temperature denoted by $D_{k, N}$ and $T_{N}$ are $\mathcal{F}_{N}$-measurable. In the next two sections we formulate and solve the stochastic dynamic portfolio optimization problems by working backwards. We first explore the single-period problems and then two-period problems. Lastly we generalize the results for the multi-period portfolio optimization problem.

\subsection{Single-period indifference price}

In this section we define states, controls, randomness, and the value functions of the stochastic dynamic programming problems corresponding to type $i$ and $j$ buyers and the issuer. We then derive the equilibrium price under the exponential utility function with a single trading opportunity. First we describe the dynamic system equations for type $i$ buyers as

$$
S_{i, n+1}=z_{i, n}\left(S_{i, n}, x_{i, n+1}, Y_{i, n+1}\right) \quad \forall n=0,1, \ldots, N-1
$$

where $S_{i, n}$ denotes a state of the dynamic system at time $\mathrm{n}$ and has the vector form $\left(V_{i, n}, P_{i, n}, W_{n}\right) . V_{i, n}$ is the type $i$ buyer's portfolio value at time $n$ and $z_{i, n}(\cdot)$ denotes some deterministic function which maps the previous state to the next state. The randomness $Y_{i, n+1}$ can be expressed as $\left(P_{i, n+1}, W_{n+1}\right)$. The last state $S_{i, N}$ has the additional randomness because terminal wealth of the type $i$ buyers is dependent on the random demand $D_{i, N}$ and temperature $T_{N}$, therefore the randomness at $N$ $Y_{i, N}$ has the form $\left(P_{i, N}, D_{i, N}, T_{N}\right)$. In addition our control $x_{i, n+1}\left(P_{i, n+1}\right)$ at time $n$ represents the payoff function of the commodity derivatives portfolio which consists of a risk-free bond and commodity derivatives. Note that $x_{i, n+1}\left(P_{n+1}\right)$ is predictable, i.e. it is $\mathcal{F}_{n}$-measurable. The type $i$ buyer's profit function (or terminal wealth) at time $N$ can be defined as

$$
\begin{aligned}
\Pi_{i, N} & =I_{i}\left(D_{i, N}, P_{i, N}\right)+x_{i, N}\left(P_{i, N}\right)+\alpha_{i, N} W_{N} \\
& =I_{i}\left(D_{i}, P_{i, N}\right)+V_{i, N}
\end{aligned}
$$

where $I_{i}\left(D_{i, N}, P_{i, N}\right)$ denotes the income of type $i$ buyers from the retail business. $\alpha_{i, N}$ and $W_{N}$ are the quantity purchased at time $N-1$ and the payoff (or price) at time $N$ of the weather derivative, respectively. Then the corresponding value function of type $i$ buyers at time $n$ can be defined as

$$
\begin{gathered}
J\left(V_{i, n}-\alpha_{n+1} W_{n}, \alpha_{n+1}\right)=\max _{\left\{x_{i, n+1}\left(P_{n+1}\right)\right\}} E_{n}\left[U_{i}\left(\Pi_{i, N}\right)\right] \\
\text { s.t. } \quad E_{n}^{\mathbb{Q}}\left[\frac{x_{i, n+1}\left(P_{i, n+1}\right)}{1+r_{n}}\right]+\alpha_{i, n+1} W_{n}-V_{i, n}=0
\end{gathered}
$$


where $r_{n}$ denotes the interest rate at time $n$. In the above self-financing trading strategy constraint the expected value of the discounted portfolio payoff under a riskneutral probability measure $\mathbb{Q}$ is the price of optimal commodity portfolio at time $n$. For each realization $p$ of the random price $P_{i, n+1}$ we will find the optimal payoff function $x_{i, n+1}(p)$ of problem (4). Carr and Madan [9] show that any twice continuously differentiable function, $f(S)$, of the terminal stock price $S$ can be replicated by a unique initial position of $f\left(S_{0}\right)-f^{\prime}\left(S_{0}\right) S_{0}$ unit discount bonds, $f^{\prime}\left(S_{0}\right)$ shares, and $f^{\prime \prime}(K) d K$ out-of-the-money options of all strikes $K$ :

$$
\begin{aligned}
f(S)= & {\left[f\left(S_{0}\right)-f^{\prime}\left(S_{0}\right) S_{0}\right]+f^{\prime}\left(S_{0}\right) S+\int_{0}^{S_{0}} f^{\prime \prime}(K)(K-S)^{+} d K } \\
& +\int_{S_{0}}^{\infty} f^{\prime \prime}(K)(S-K)^{+} d K
\end{aligned}
$$

However, the replication of the optimal payoff function in an incomplete market is out of scope of this paper and we will not elaborate on this issue any further. We will just specify the closed form of the optimal payoff function in each period.

To solve the stochastic dynamic programming problem (4), we need to work backwards. In addition the problem in each period is a convex programming problem because the concavity of the objective function and the convexity of the feasible set. Therefore we formulate the original constrained problem as a Lagrangian relaxation problem and the optimal solutions of the relaxed problem will have no duality gap. At time $N$ we have

$$
J\left(V_{i, N}\right)=E_{N}\left[U_{i}\left(\Pi_{i, N}\right)\right]=U_{i}\left(\Pi_{i, N}\right)=U_{i}\left(I_{i}\left(D_{i}, P_{i, N}\right)+V_{i, N}\right)
$$

At time $N-1$ the buyers' maximization problem is the same as in a single period problem. The corresponding single-period problem is

$$
\begin{gathered}
J\left(V_{i, N-1}-\alpha_{i, N} W_{N-1}, \alpha_{i, N}\right)=\max _{\left\{x_{i, N}\left(P_{i, N}\right)\right\}} E_{N-1}\left[U_{i}\left(\Pi_{i, N}\right)\right] \\
\text { s.t. } \quad E_{N-1}^{\mathbb{Q}}\left[\frac{x_{i, N}\left(P_{i, N}\right)}{1+r_{N-1}}\right]+\alpha_{i, N} W_{N-1}-V_{i, N-1}=0
\end{gathered}
$$

Proposition 1 The optimal payoff function $x_{i, N}\left(P_{i, N}\right)$ of problem (7) is

$$
\begin{aligned}
x_{i, N}^{w *}\left(P_{i, N}\right)= & \frac{1}{a_{i}}\left(\ln E_{N-1}\left[\exp \left(-a_{i}\left(I_{i}+\alpha_{i, N} W_{N}\right)\right) \mid P_{i, N}\right]\right. \\
& -E_{N-1}^{\mathbb{Q}}\left[\ln E_{N-1}\left[\exp \left(-a_{i}\left(I_{i}+\alpha_{i, N} W_{N}\right)\right) \mid P_{i, N}\right]\right] \\
& -\left(\ln \frac{g_{i, N}\left(P_{i, N}\right)}{f_{i, N}\left(P_{i, N}\right)}-E_{N-1}^{\mathbb{Q}}\left[\ln \frac{g_{i, N}\left(P_{i, N}\right)}{f_{i, N}\left(P_{i, N}\right)}\right]\right) \\
& \left.+a_{i}\left(1+r_{N-1}\right)\left(V_{i, N-1}-\alpha_{i, N} W_{N-1}\right)\right)
\end{aligned}
$$


where $f_{i, N}\left(P_{i, N}\right)$ and $g_{i, N}\left(P_{i, N}\right)$ are probability density functions of the type $i$ commodity spot price under the real world probability measure $\mathbb{P}$ and a risk neutral probability measure $\mathbb{Q}$, respectively and $r_{N-1}$ is the interest rate at time $N-1$.

The proof is provided in Appendix.

To get the indifference price for type $i$ buyers, we need to solve the expected utility maximization problem without the weather derivative.

$$
\begin{gathered}
J\left(V_{i, N-1}, 0\right)=\max _{\left\{x_{i, N}\left(P_{i, N}\right)\right\}} E_{N-1}\left[U_{i}\left(I_{i}+x_{i, N}\left(P_{i, N}\right)\right)\right] \\
\text { s.t. } \quad E_{N-1}^{\mathbb{Q}}\left[\frac{x_{i, N}\left(P_{i, N}\right)}{1+r_{N-1}}\right]-V_{i, N-1}=0
\end{gathered}
$$

Proposition 1 implies the following optimal payoff function in case of no weather derivative.

$$
\begin{aligned}
\left.x_{i, N}^{n *}\left(P_{i, N}\right)\right)= & \frac{1}{a_{i}}\left(\ln E_{N-1}\left[\exp \left(-a_{i} I_{i}\right) \mid P_{i, N}\right]-E_{N-1}^{\mathbb{Q}}\left[\ln E_{N-1}\left[\exp \left(-a_{i} I_{i}\right) \mid P_{i, N}\right]\right]\right. \\
& \left.-\left(\ln \frac{g\left(P_{i, N}\right)}{f\left(P_{i, N}\right)}-E_{N-1}^{\mathbb{Q}}\left[\ln \frac{g\left(P_{i, N}\right)}{f\left(P_{i, N}\right)}\right]\right)+a_{i}\left(1+r_{N-1}\right) V_{i, N-1}\right)
\end{aligned}
$$

Now we have the maximized expected utility function with and without weather derivative and therefore, the indifference price can be obtained from the following equation.

$$
J\left(V_{i, N-1}-\alpha_{i, N} W_{N-1}, \alpha_{i, N}\right)=J\left(V_{i, N-1}, 0\right)
$$

As a result, the indifference price of type $i$ buyers has the form of

$$
W_{N-1}=\frac{1}{a_{i}\left(1+r_{N-1}\right) \alpha_{i, N}} \ln \frac{\Delta_{i, N-1}}{\Lambda_{i, N-1}}=h_{i, N-1}\left(\alpha_{i, N}\right)
$$

where the Greeks are given by

$$
\begin{aligned}
\Delta_{i, N-1}= & E_{N-1}\left[\frac{\exp \left(-a_{i} I_{i}\right) \frac{g_{i, N}\left(P_{i, N}\right)}{f_{i, N}\left(P_{i, N}\right)}}{E_{N-1}\left[\exp \left(-a_{i} I_{i}\right) \mid P_{i, N}\right]}\right] \\
& \times \exp \left(E^{\mathbb{Q}}\left[\ln E_{N-1}\left[\exp \left(-a_{i} I_{i}\right) \mid P_{i, N}\right]\right]\right) \\
\Lambda_{i, N-1}= & E_{N-1}\left[\frac{\exp \left(-a_{i}\left(I_{i}+\alpha_{N} W_{N}\right)\right) \frac{g_{i, N}\left(P_{i, N}\right)}{f_{i, N}\left(P_{i, N}\right)}}{E_{N-1}\left[\exp \left(-a_{i}\left(I_{i}+\alpha_{N} W_{N}\right)\right) \mid P_{i, N}\right]}\right] \\
& \times \exp \left(E^{\mathbb{Q}}\left[\ln E_{N-1}\left[\exp \left(-a_{i}\left(I_{i}+\alpha_{N} W_{N}\right)\right) \mid P_{i, N}\right]\right]\right)
\end{aligned}
$$

Note that the indifference price of the weather derivative is independent of the portfolio value $V_{i, N-1}$ due to the Constant Absolute Risk Aversion (CARA) property of the exponential utility function. 
Next we define the dynamic system equations of the type $j$ buyers as

$$
S_{j, n+1}=z_{j, n}\left(S_{j, n}, \beta_{j, n+1}, Y_{j, n+1}\right) \quad \forall n=0,1, \ldots, N-1
$$

where a state $S_{j, n}$ is the vector form of $\left(V_{j, n}, W_{n}\right)$, the control $\beta_{j, n+1}$ is the risk-free bond position, and the randomness $Y_{j, n+1}$ has the single term $W_{n+1}$. The randomness of the last state $S_{j, N}$ includes the additional random variables because the income function of terminal wealth of type $j$ buyers has the random price and the random demand of type $j$ commodity. So $Y_{j, N}$ has the vector form $\left(P_{j, N}, D_{j, N}, T_{N}\right)$. The profit function (or terminal wealth) of the type $j$ buyers is

$$
\Pi_{j, N}=I_{j}\left(D_{j, N}, P_{j, N}\right)+\alpha_{j, N} W_{N}+\beta_{j, N} B_{N}
$$

The type $j$ buyers at time $n$ have the following utility maximization problem if the weather derivative is included in their portfolios.

$$
\begin{gathered}
J\left(V_{j, n}-\alpha_{j, n+1} W_{n}, \alpha_{j, n+1}\right)=\max _{\beta_{j, n+1}} E_{n}\left[U_{j}\left(\Pi_{j, N}\right)\right] \\
\text { s.t. } \quad \alpha_{j, n+1} W_{n}+\beta_{j, n+1} B_{n}-V_{j, n}=0
\end{gathered}
$$

At time $N-1$ the single-period problem of the type $\mathrm{j}$ buyers can be simplified as an unconstrained problem if we plug $\beta_{j, N}$ obtained from the self-financing constraint into the objective function. Then, the reformulated problem is

$$
\begin{aligned}
& J\left(V_{j, N-1}-\alpha_{j, N} W_{N-1}, \alpha_{j, N}\right) \\
& \quad=E_{N-1}\left[U_{j}\left(I_{j}+\alpha_{j, N} W_{N}+\left(V_{j, N-1}-\alpha_{j, N} W_{N-1}\right)\left(1+r_{N-1}\right)\right)\right]
\end{aligned}
$$

To get the indifference price we need to consider the problem without the weather derivative in the portfolio.

$$
J\left(V_{j, N-1}, 0\right)=E_{N-1}\left[U_{j}\left(I_{j}+V_{j, N-1}\left(1+r_{N-1}\right)\right)\right]
$$

Equating the right hand sides of (18) and (19) gives the indifference price of type $j$ buyers as

$$
\begin{aligned}
W_{N-1} & =\frac{1}{a_{j}\left(1+r_{N-1}\right) \alpha_{j, N}} \ln \frac{E_{N-1}\left[\exp \left(-a_{j} I_{j}\right)\right]}{E_{N-1}\left[\exp \left(-a_{j}\left(I_{j}+\alpha_{j, N} W_{N}\right)\right)\right]} \\
& =h_{j, N-1}\left(\alpha_{j, N}\right)
\end{aligned}
$$

So far we have studied the buyers' problems and in this paragraph we will explore the issuer's problem. We assume that the issuer is a pure financial firm, which can trade only risk-free bonds and weather derivatives but not commodity derivatives. The issuer is assumed to be able to sell or buy back outstanding weather derivative in any period. When the weather derivatives are sold in the market the issuer will receive the selling price and at maturity settle the payoff of the weather derivative. The issuer's system equations are similar to type $j$ buyers except at the terminal time since the issuer does not have the income function which contains two random 
variables, price and quantity for the commodity. Then the issuer's dynamic system equations can be expressed as:

$$
S_{m, n+1}=z_{m, n}\left(S_{m, n}, \beta_{m, n+1}, Y_{m, n+1}\right) \quad \forall n=0,1, \ldots, N-1
$$

where a state $S_{m, n}$ is characterized by the vector $\left(V_{m, n}, W_{n}\right)$ and the randomness $Y_{m, n+1}$ of the dynamic system equations is the weather derivative price $W_{n+1}$. The issuer's value function is then,

$$
\begin{aligned}
& J\left(V_{m, n}+\alpha_{m, n+1} W_{n},-\alpha_{m, n+1}\right)=\max _{\beta_{m, n+1}} E_{n}\left[U_{j}\left(-\alpha_{m, N} W_{N}+\beta_{m, N} B_{N}\right)\right] \\
& \text { s.t. } \quad \alpha_{m, n+1} W_{n}+V_{m, n}=\beta_{m, n+1} B_{n}
\end{aligned}
$$

The issuer's indifference price at $N-1$, therefore, can be calculated from the following equation.

$$
\begin{aligned}
J & \left(V_{m, N-1}+\alpha_{m, N} W_{N-1},-\alpha_{m, N}\right) \\
& =E_{N-1}\left[U_{m}\left(\left(V_{m, N-1}+\alpha_{m, N-1} W_{N-1}\right)\left(1+r_{N-1}\right)-\alpha_{m, N-1} W_{N}\right)\right] \\
& =E_{N-1}\left[U_{m}\left(V_{m, N-1}\left(1+r_{N-1}\right)\right)\right]=J\left(V_{m, N-1}, 0\right)
\end{aligned}
$$

After simplifying the above equation we have the following indifference price for the issuer.

$$
W_{N-1}=\frac{\ln E_{N-1}\left[\exp \left(a_{m} \alpha_{m, N} W_{N}\right)\right]}{a_{m}\left(1+r_{N-1}\right) \alpha_{m, N}}=h_{m, N-1}\left(\alpha_{m, N}\right)
$$

Now we have the supply and demand functions for the weather derivative at $N-1$. If the supply and demand quantities are a function of price then we can directly apply the market clearing condition i.e. a zero net supply equation. In our case the price, however, is a function of quantities and the inverse functions of the derived supply and demand are hard to get, so we need to solve the following system of equations numerically. Then we can determine the equilibrium price $W_{N-1}^{*}$ and the optimal choices $\alpha_{k, N}^{*}$ for all $k$ in $\{i, j, m\}$ which clear the market.

$$
\begin{gathered}
W_{N-1}^{*}=h_{i, N-1}\left(\alpha_{i, N}^{*}\right)=h_{j, N-1}\left(\alpha_{j, N}^{*}\right)=h_{m, N-1}\left(\alpha_{m, N}^{*}\right) \quad \forall i, j \\
\sum_{i} \alpha_{i, N}^{*}+\sum_{j} \alpha_{j, N}^{*}=\alpha_{m, N}^{*}
\end{gathered}
$$

By substituting the derived optimal portfolio positions and the equilibrium price into the objective function we can find the value function of the type $i$ buyers as

$$
\begin{aligned}
J\left(V_{i, N-1}-\alpha_{N}^{*} W_{N-1}^{*}, \alpha_{N}^{*}\right) & =J_{i, N-1}^{*}\left(V_{i, N-1}\right) \\
& =-\frac{1}{a_{i}} \exp \left(-a_{i}\left(1+r_{N-1}\right) V_{i, N-1}\right) \Theta_{i, N-1}
\end{aligned}
$$


where $\Theta_{i, N-1}$ is an $\mathcal{F}_{N-1}$-measurable random variable, independent on $V_{i, N-1}$, and has the form

$$
\begin{aligned}
\Theta_{i, N-1}= & \exp \left(a_{i}\left(1+r_{N-1}\right) \alpha_{i, N}^{*} W_{N-1}^{*}\right. \\
& \left.+E_{N-1}^{\mathbb{Q}}\left[\ln E_{N-1}\left[\exp \left(-a_{i}\left(I_{i}+\alpha_{i, N}^{*} W_{N}\right)\right) \mid P_{i, N}\right]-\ln \frac{g_{i, N}\left(P_{i, N}\right)}{f_{i, N}\left(P_{i, N}\right)}\right]\right) \\
& \times E_{N-1}\left[\frac{\exp \left(-a_{i}\left(I_{i}+\alpha_{i, N}^{*} W_{N}\right)\right) \frac{g_{i, N}\left(P_{i, N}\right)}{f_{i, N}\left(P_{i, N}\right)}}{E_{N-1}\left[\exp \left(-a_{i}\left(I_{i}+\alpha_{i, N}^{*} W_{N}\right) \mid P_{i, N}\right)\right]}\right]
\end{aligned}
$$

In (27) we use $J_{i, N-1}^{*}\left(V_{i, N-1}\right)$ as short hand notation for $J\left(V_{i, N-1}-\alpha_{N}^{*} W_{N-1}^{*}, \alpha_{N}^{*}\right)$. From now on we will also use this short hand notation for the type $j$ buyers and the issuer. Similarly, the value function of type $j$ buyers will be

$$
\begin{aligned}
J\left(V_{j, N-1}-\alpha_{N}^{*} W_{N-1}^{*}, \alpha_{N}^{*}\right) & =J_{j, N-1}^{*}\left(V_{j, N-1}\right) \\
& =-\frac{1}{a_{j}} \exp \left(-a_{j}\left(1+r_{N-1}\right) V_{j, N-1}\right) \Theta_{j, N-1}
\end{aligned}
$$

where $\Theta_{j, N_{1}}$ is again independent of $V_{j, N-1}, \mathcal{F}_{N-1}$-measurable, and has the form:

$$
\Theta_{j, N_{1}}=\exp \left(a_{j}\left(1+r_{N-1}\right) \alpha_{j, N}^{*} W_{N-1}^{*}\right) E_{N-1}\left[\exp \left(-a_{j}\left(I_{j}+\alpha_{j, N}^{*} W_{N}\right)\right)\right]
$$

Finally, the value function for the issuer will be

$$
\begin{aligned}
J\left(V_{m, N-1}+\alpha_{N}^{*} W_{N-1}^{*},-\alpha_{N}^{*}\right) & =J_{m, N-1}^{*}\left(V_{m, N-1}\right) \\
& =-\frac{1}{a_{m}} \exp \left(-a_{m}\left(1+r_{N-1}\right) V_{m, N-1}\right) \Theta_{m, N-1} \\
& =-\frac{1}{a_{m}} \exp \left(-a_{m}\left(1+r_{N-1}\right) V_{m, N-1}\right)
\end{aligned}
$$

The last equality comes from the indifference pricing equality because $\Theta_{m, N-1}$ has the form:

$$
\Theta_{m, N-1}=\exp \left(-a_{m}\left(1+r_{N-1}\right) \alpha_{m, N}^{*} W_{N-1}^{*}\right) E_{N-1}\left[\exp \left(a_{m} \alpha_{m, N}^{*} W_{N}\right)\right]=1
$$

Note that all value functions are again exponential forms multiplied by $\mathcal{F}_{N-1^{-}}$measurable random variables and therefore, we can see the preservation for the dynamic programming algorithm.

\subsection{Multi-period indifference price}

Now we concentrate on a multi-period indifference pricing problem. Consider the indifference pricing model for type $i$ buyers, first. In the previous section we already solved a single-period problem at $N-1$, so in this section we will start from time $N-2$ and generalize the result for $N$ periods. By applying the Bellman's Principle 
of Optimality which states that given an initial decision the remaining decisions must be optimal, we can see that:

$$
\begin{aligned}
& \max _{\left\{x_{i, N-1}, \lambda_{i, N-1}\right\}} E_{N-2}\left[U_{i}\left(\Pi_{i, N}\right)\right]-\lambda_{i, N-1} C_{i, N-2} \\
= & \max _{\left\{x_{i, N-1}, \lambda_{i, N-1}\right\}} E_{N-2}\left[\max _{\left\{x_{i, N}, \lambda_{i, N}\right\}} U_{i}\left(\Pi_{i, N}\right)-\lambda_{i, N} C_{i, N-1}\right] \\
& \quad-\lambda_{i, N-1} C_{, N-2}
\end{aligned}
$$

where $C_{i, n}$ denotes the self-financing constraint at time $n$. If we use the law of iterated expectations, then we can find the recursive form known as the Bellman equation.

$$
\begin{aligned}
& J\left(V_{i, N-2}-\alpha_{i, N-1} W_{N-2}, \alpha_{i, N-1}\right) \\
& =\max _{\left\{x_{i, N-1}, \lambda_{i, N-1}\right\}} E_{N-2}\left[\max _{\left\{x_{i, N}, \lambda_{i, N}\right\}} E_{N-1}\left[U_{i}\left(\Pi_{i, N}\right)\right]-\lambda_{i, N} C_{i, N-1}\right]-\lambda_{i, N-1} C_{i, N-2} \\
& =\max _{\left\{x_{i, N-1}, \lambda_{i, N-1}\right\}} E_{N-2}\left[J_{i, N-1}^{*}\left(V_{i, N-1}\right)\right]-\lambda_{i, N-1} C_{i, N-2}
\end{aligned}
$$

Define $R_{n}$ as $\prod_{i=n}^{N-1}\left(1+r_{i}\right)$. By solving the problem (34) we derive the following optimal solution at time $N-2$.

Proposition 2 The optimal payoff function $x_{i, N-1}\left(P_{i, N-1}\right)$ at $N-2$ is

$$
\begin{aligned}
x_{i, N-1}^{w *} & \left(P_{i, N-1}\right) \\
= & \frac{1}{a_{i} R_{N-1}}\left(\ln E_{N-2}\left[\exp \left(-a_{i} R_{N-1} \alpha_{i, N-1} W_{N-1}\right) \Theta_{i, N-1} \mid P_{i, N-1}\right]\right. \\
& -E_{N-2}^{\mathbb{Q}}\left[\ln E_{N-2}\left[\exp \left(-a_{i} R_{N-1} \alpha_{i, N-1} W_{N-1}\right) \Theta_{i, N-1} \mid P_{i, N-1}\right]\right] \\
& -\left(\ln \frac{g_{i, N-1}\left(P_{i, N-1}\right)}{f_{i, N-1}\left(P_{i, N-1}\right)}-E_{N-2}^{\mathbb{Q}}\left[\ln \frac{g_{i, N-1}\left(P_{i, N-1}\right)}{f_{i, N-1}\left(P_{i, N-1}\right)}\right]\right) \\
& \left.+a_{i} R_{N-2}\left(V_{i, N-2}-\alpha_{i, N-1} W_{N-2}\right)\right)
\end{aligned}
$$

Proof Similarly to the optimal solutions at $N-1$ derived in the Appendix, taking partial derivatives provides the optimality conditions at $N-2$ as

$$
\begin{aligned}
\frac{\partial L_{i, N-2}}{\partial x_{i, N-1}(p)}= & E_{N-2}\left[J_{i, N-1}^{* \prime}\left(V_{i, N-1}\right) \frac{\partial V_{i, N-1}}{\partial x_{i, N-1}(p)} \mid p\right] f_{i, N-1}(p) \\
& -\lambda_{i, N-1} \frac{g_{i, N-1}(p)}{1+r_{N-2}}=0 \\
\frac{\partial L_{i, N-2}}{\partial \lambda_{i, N-1}}= & V_{i, N-2}-\left(E_{N-2}^{\mathbb{Q}}\left[\frac{x_{i, N-1}\left(P_{i, N-1}\right)}{1+r_{N-2}}\right]+\alpha_{i, N-1} W_{N-2}\right)=0
\end{aligned}
$$

If we plug the value function at time $N-1$ (27) into the above optimality condition (36) and combine with the equation $V_{i, N-1}=x_{i, N-1}\left(P_{i, N-1}\right)+\alpha_{i, N-1} W_{N-1}$ then, 
we have

$$
\begin{aligned}
\frac{\partial L_{i, N-2}}{\partial x_{i, N-1}(p)}= & R_{N-1} \exp \left(-a_{i} R_{N-1} x_{i, N-1}(p)\right) \\
& \times E_{N-2}\left[\exp \left(-a_{i} R_{N-1} \alpha_{i, N-1} W_{N-1}\right) \Theta_{i, N-1} \mid p\right] f_{i, N-1}(p) \\
& -\lambda_{i, N-1} \frac{g_{i, N-1}(p)}{1+r_{N-2}}=0
\end{aligned}
$$

After simplifying the above equation (38) we get

$$
\begin{aligned}
x_{i, N-1}(p)= & \frac{1}{a_{i} R_{N-1}}\left(\ln E_{N-2}\left[\exp \left(-a_{i} R_{N-1} \alpha_{i, N-1} W_{N-1}\right) \Theta_{i, N-1} \mid p\right]\right. \\
& \left.-\ln \frac{\lambda_{i, N-1}}{R_{N-2}}-\ln \frac{g_{i, N-1}(p)}{f_{i, N-1}(p)}\right)
\end{aligned}
$$

By taking expectation under $\mathbb{Q}$ and combining with (37) we have

$$
\begin{aligned}
\ln \frac{\lambda_{i, N-1}}{R_{N-2}}= & E_{N-2}^{\mathbb{Q}}\left[\ln E_{N-2}\left[\exp \left(-a_{i} R_{N-1} \alpha_{i, N-1} W_{N}\right) \Theta_{i, N-1} \mid P_{i, N-1}\right]\right] \\
& -E_{N-2}^{\mathbb{Q}}\left[\ln \frac{g_{i, N-1}\left(P_{i, N-1}\right)}{f_{i, N-1}\left(P_{i, N-1}\right)}\right] \\
& -a_{i} R_{N-2}\left(V_{i, N-2}-\alpha_{i, N-1} W_{N-2}\right)
\end{aligned}
$$

If we substitute (40) into (39) we obtain the resulting optimal payoff function at time $N-2$.

To get the indifference price for type i buyers, we need $J\left(V_{i, N-2}, 0\right)$ and the optimal payoff function in Proposition 2 implies

$$
\begin{aligned}
x_{i, N-1}^{n *}\left(P_{i, N-1}\right)= & \frac{1}{a_{i} R_{N-1}}\left(\ln E_{N-2}\left[\Theta_{i, N-1} \mid P_{i, N-1}\right]\right. \\
& -E_{N-2}^{\mathbb{Q}}\left[\ln E_{N-2}\left[\Theta_{i, N-1} \mid P_{i, N-1}\right]\right] \\
& -\left(\ln \frac{g_{i, N-1}\left(P_{i, N-1}\right)}{f_{i, N-1}\left(P_{i, N-1}\right)}-E_{N-2}^{\mathbb{Q}}\left[\ln \frac{g_{i, N-1}\left(P_{i, N}\right)}{f_{i, N-1}\left(P_{i, N}\right)}\right]\right) \\
& \left.+a_{i} R_{N-2} V_{i, N-2}\right)
\end{aligned}
$$

By setting $J\left(V_{i, N-2}-\alpha_{i, N-1} W_{N-2}, \alpha_{i, N-1}\right)$ and $J\left(V_{i, N-2}, 0\right)$ equal we have the indifference price for the type $i$ buyers as

$$
W_{N-2}=\frac{1}{a_{i} R_{N-2} \alpha_{i, N-1}} \ln \frac{\Delta_{i, N-2}}{\Lambda_{i, N-2}}=h_{i, N-2}\left(\alpha_{i, N-1}\right)
$$


where we have

$$
\begin{aligned}
\Delta_{i, N-2}= & E_{N-2}\left[\frac{\Theta_{i, N-1} \frac{g_{i, N-1}\left(P_{i, N-1}\right)}{f_{i, N-1}\left(P_{i, N-1}\right)}}{E_{N-2}\left[\Theta_{i, N-1} \mid P_{i, N-1}\right]}\right] \\
& \times \exp \left(E_{N-2}^{\mathbb{Q}}\left[\ln E_{N-2}\left[\Theta_{i, N-1} \mid P_{i, N-1}\right]\right]\right) \\
\Lambda_{i, N-2}= & E_{N-2}\left[\frac{\exp \left(-a_{i} R_{N-1} \alpha_{i, N-1} W_{N-1}\right) \Theta_{i, N-1} \frac{g_{i, N-1}\left(P_{i, N-1}\right)}{f_{i, N-1}\left(P_{i, N-1}\right)}}{E_{N-2}\left[\exp \left(-a_{i} R_{N-1} \alpha_{i, N-1} W_{N-1}\right) \Theta_{i, N-1} \mid P_{i, N-1}\right]}\right] \\
& \times \exp \left(E_{N-2}^{\mathbb{Q}}\left[\ln E_{N-2}\left[\exp \left(-a_{i} R_{N-1} \alpha_{i, N-1} W_{N-1}\right) \Theta_{i, N-1} \mid P_{i, N-1}\right]\right]\right)
\end{aligned}
$$

Based on the pattern of the optimality condition at time $N-1$ and $N-2$, inductive reasoning implies that the Bellman equation can be written as

$$
\begin{aligned}
& J_{i, N}=U_{i}\left(\Pi_{i, N}\right) \\
& J_{i, n}^{*}\left(V_{i, n}\right)=\max _{\left\{x_{i, n+1}, \lambda_{i, n+1}\right\}} E_{n}\left[J_{i, n+1}^{*}\left(V_{i, n+1}\right)\right]-\lambda_{i, n+1} C_{i, n} \\
& \quad \forall n=0,1, \ldots, N-1
\end{aligned}
$$

and, therefore, we can induce the optimality conditions at time $n$ as

$$
\begin{aligned}
\frac{\partial L_{i, n}}{\partial x_{i, n+1}(p)}= & E_{n}\left[J_{i, n+1}^{*^{\prime}}\left(V_{i, n+1}\right) \frac{\partial V_{i, n+1}}{\partial x_{i, n+1}(p)} \mid p\right] f_{i, n+1}(p) \\
& -\lambda_{i, n+1} \frac{g_{i, n+1}(p)}{1+r_{n}}=0 \\
\frac{\partial L_{i, n}}{\partial \lambda_{i, n+1}}=V_{i, n}- & \left(E_{n}^{\mathbb{Q}}\left[\frac{x_{i, n+1}\left(P_{i, n+1}\right)}{1+r_{n}}\right]+\alpha_{i, n+1} W_{n}\right)=0
\end{aligned}
$$

By solving the above optimality conditions or by induction we can obtain the following optimal payoff function.

Proposition 3 The optimal payoff function $x_{i, n+1}^{w *}\left(P_{i, n+1}\right)$ at $n$ can be expressed as

$$
\begin{array}{rl}
x_{i, n+1}^{w *}\left(P_{i, n+1}\right)= & \frac{1}{a_{i} R_{n+1}}\left(\ln E_{n}\left[\exp \left(-a_{i} R_{n+1} \alpha_{i, n+1} W_{n+1}\right) \Theta_{i, n+1} \mid P_{i, n+1}\right]\right. \\
& -E_{n}^{\mathbb{Q}}\left[\ln E_{n}\left[\exp \left(-a_{i} R_{n+1} \alpha_{i, n+1} W_{n+1}\right) \Theta_{i, n+1} \mid P_{i, n+1}\right]\right] \\
& -\left(\ln \frac{g_{i, n+1}\left(P_{i, n+1}\right)}{f_{i, n+1}\left(P_{i, n+1}\right)}-E_{n}^{\mathbb{Q}}\left[\ln \frac{g_{i, n+1}\left(P_{i, n+1}\right)}{f_{i, n+1}\left(P_{i, n+1}\right)}\right]\right) \\
& \left.+a_{i} R_{n}\left(V_{i, n}-\alpha_{i, n+1} W_{n}\right)\right) \\
\forall n=0,1, \ldots, N & N-2
\end{array}
$$


Moreover the indifference price of type $i$ buyers at time $n$ will be

$$
W_{n}=\frac{1}{a_{i} R_{n} \alpha_{i, n+1}} \ln \frac{\Delta_{i, n}}{\Lambda_{i, n}}=h_{i, n}\left(\alpha_{i, n+1}\right)
$$

where we have

$$
\begin{aligned}
\Delta_{i, n}= & E_{n}\left[\frac{\left.\left.\Theta_{i, n+1} \frac{g_{i, n+1}\left(P_{i, n+1}\right)}{f_{i, n+1}\left(P_{i, n+1}\right)}\right] \Theta_{i, n+1} \mid P_{i, n+1}\right]}{E_{n}}\right] \\
& \times \exp \left(E_{n}^{\mathbb{Q}}\left[\ln E_{n}\left[\Theta_{i, n+1} \mid P_{i, n+1}\right]\right]\right) \\
\Lambda_{i, n}= & E_{n}\left[\frac{\exp \left(-a_{i} R_{n+1} \alpha_{i, n+1} W_{n+1}\right) \Theta_{i, n+1} \frac{g_{i, n+1}\left(P_{i, n+1}\right)}{f_{i, n+1}\left(P_{i, n+1}\right)}}{E_{n}\left[\exp \left(-a_{i} R_{n+1} \alpha_{i, n+1} W_{n+1}\right) \Theta_{i, n+1} \mid P_{i, n+1}\right]}\right] \\
& \times \exp \left(E_{n}^{\mathbb{Q}}\left[\ln E_{n}\left[\exp \left(-a_{i} R_{n+1} \alpha_{i, n+1} W_{n+1}\right) \Theta_{i, n+1} \mid P_{i, n+1}\right]\right]\right)
\end{aligned}
$$

Next we derive the optimal choices and the indifference price for type $j$ buyers in a multi-period setting. Recall $J_{j, N-1}^{*}\left(V_{j, N-1}\right)$ in (29). After substituting the selffinancing constraint into the objective function the dynamic programming algorithm and the indifference price equation imply

$$
\begin{aligned}
& J\left(V_{j, N-2}-\alpha_{j, N-1} W_{N-2}, \alpha_{j, N-1}\right)=E_{N-2}\left[J_{j, N-1}^{*}\left(V_{j, N-1}\right)\right] \\
& =E_{N-2}\left[-\frac{1}{a_{j}} \exp \left(-a_{j} R_{N-1}\left(\left(V_{j, N-2}-\alpha_{j, N-1} W_{N-2}\right)\left(1+r_{N-2}\right)\right.\right.\right. \\
& \left.\left.\left.\quad+\alpha_{j, N-1} W_{N-1}\right)\right) \Theta_{j, N-1}\right] \\
& =E_{N-2}\left[-\frac{1}{a_{j}} \exp \left(-a_{j} R_{N-2} V_{j, N-2}\right) \Theta_{j, N-1}\right]=J\left(V_{j, N-2}, 0\right)
\end{aligned}
$$

After simplifying the above (50) we have the following indifference price for type $j$ buyers at $N-2$.

$$
\begin{aligned}
W_{N-2} & =\frac{1}{a_{j} R_{N-2} \alpha_{j, N-1}} \ln \left(\frac{E_{N-2}\left[\Theta_{j, N-1}\right]}{E_{N-2}\left[\exp \left(-a_{j} R_{N-1} \alpha_{j, N-1} W_{N-1}\right) \Theta_{j, N-1}\right]}\right) \\
& =h_{j, N-2}\left(\alpha_{j, N-1}\right)
\end{aligned}
$$

In general, by inductive reasoning, the indifference price for type $j$ buyers can be expressed as

$$
\begin{aligned}
W_{n} & =\frac{1}{a_{j} R_{n} \alpha_{j, n+1}} \ln \left(\frac{E_{n}\left[\Theta_{j, n+1}\right]}{E_{n}\left[\exp \left(-a_{j} R_{n+1} \alpha_{j, n+1} W_{n+1}\right) \Theta_{j, n+1}\right]}\right) \\
& =h_{j, n}\left(\alpha_{j, n+1}\right) \quad \forall n=0,1, \ldots, N-2
\end{aligned}
$$

Lastly consider the issuer's selling price at which she is indifferent between not selling the weather derivative versus selling the weather derivative at the selling price 
today and settling the claim at maturity. The issuer's problem is similar to type $j$ buyers' problem in the sense that she has only two tradable assets, the risk-free bond and the weather derivative but the incoming and outgoing cash flows are opposite to the type $j$ buyers. Therefore, the issuer's portfolio value at $n$ will be

$$
V_{m, n}=\left(V_{m, n-1}+\alpha_{m, n} W_{n-1}\right)\left(1+r_{n-1}\right)-\alpha_{m, n} W_{n}
$$

At $N-2$ the indifference selling price of the weather derivative can be obtained from the following equation.

$$
\begin{aligned}
J\left(V_{m, N-2}+\alpha_{m, N-1} W_{N-2},-\alpha_{m, N-1}\right)=E_{N-2}\left[J_{m, N-1}^{*}\left(V_{m, N-1}\right)\right] \\
=E_{N-2}\left[-\frac{1}{a_{m}} \exp \left(-a_{m} R_{N-1}\left(\left(V_{m, N-2}+\alpha_{m, N-1} W_{N-2}\right)\left(1+r_{N-2}\right)\right.\right.\right. \\
\left.\left.\left.\quad-\alpha_{m, N-1} W_{N-1}\right)\right)\right] \\
=E_{N-2}\left[-\frac{1}{a_{m}} \exp \left(-a_{m} R_{N-2} V_{m, N-2}\right)\right]=J\left(V_{m, N-2}, 0\right)
\end{aligned}
$$

After simplifying the above equation (54), the indifference selling price of the weather derivative at $N-2$ will be

$$
\begin{aligned}
W_{N-2} & =\frac{1}{a_{m} R_{N-2} \alpha_{m, N-1}} \ln \left(E_{N-2}\left[\exp \left(a_{m} R_{N-1} \alpha_{m, N-1} W_{N-1}\right)\right)\right. \\
& =h_{m, N-2}\left(\alpha_{m, N-1}\right)
\end{aligned}
$$

By induction the indifference selling price at time $n$ can be obtained as

$$
\begin{aligned}
W_{n} & =\frac{1}{a_{m} R_{n} \alpha_{m, n+1}} \ln \left(E_{n}\left[\exp \left(a_{m} R_{n+1} \alpha_{m, n+1} W_{n+1}\right)\right]\right) \\
& =h_{m, n}\left(\alpha_{m, n+1}\right) \quad \forall n=0,1, \ldots, N-2
\end{aligned}
$$

We have found the demand and supply functions for the weather derivative at time $\mathrm{n}$ based on the indifference pricing model. The equilibrium price $W_{n}^{*}$ and the optimal choices $\alpha_{k, n+1}^{*}$ of the buyers and the issuer can be recursively determined from the following market clearing conditions.

$$
\begin{gathered}
W_{n}^{*}=h_{i, n}\left(\alpha_{i, n+1}^{*}\right)=h_{j, n}\left(\alpha_{j, n+1}^{*}\right)=h_{m, n}\left(\alpha_{m, n+1}^{*}\right) \quad \forall i, j \\
\sum_{i} \alpha_{i, n+1}^{*}+\sum_{j} \alpha_{j, n+1}^{*}=\alpha_{m, n+1}^{*}
\end{gathered}
$$

In each period the derived equilibrium price and optimal choices of the weather derivative provide the value functions for type $i$ and $j$ buyers and the issuer recursively. Here we derive the value functions at time $N-2$ based on the previous results and then generalize the solutions. The value function of type $i$ buyers at time 
$N-2$ can be calculated by substituting the optimal payoff function from Proposition 2 into (34). Then, we have

$$
\begin{aligned}
J\left(V_{i, N-2}-\alpha_{N-1}^{*} W_{N-2}^{*}, \alpha_{N-1}^{*}\right) & =J_{i, N-2}^{*}\left(V_{i, N-2}\right) \\
& =-\frac{1}{a_{i}} \exp \left(-a_{i} R_{N-2} V_{i, N-2}\right) \Theta_{i, N-2}
\end{aligned}
$$

where $\Theta_{i, N-2}$ is $\mathcal{F}_{N-2}$-measurable, independent of $V_{i, N-2}$, and has the form

$$
\begin{aligned}
\Theta_{i, N-2}= & \exp \left(a_{i} R_{N-2} \alpha_{i, N-1}^{*} W_{N-2}^{*}-E_{N-2}^{\mathbb{Q}}\left[\frac{g_{i, N-1}\left(P_{i, N-1}\right)}{f_{i, N-1}\left(P_{i, N-1}\right)}\right]\right. \\
& \left.+E_{N-2}^{\mathbb{Q}}\left[\ln E_{N-2}\left[\exp \left(-a_{i} R_{N-1} \alpha_{i, N-1}^{*} W_{N-1}\right) \Theta_{i, N-1} \mid P_{i, N-1}\right]\right]\right) \\
& \times E_{N-2}\left[\frac{\exp \left(-a_{i} R_{N-1} \alpha_{i, N-1}^{*} W_{N-1}\right) \Theta_{i, N-1}}{E_{N-2}\left[\exp \left(-a_{i} R_{N-1} \alpha_{i, N-1}^{*} W_{N-1}\right) \Theta_{i, N-1} \mid P_{i, N-1}\right]}\right. \\
& \left.\times \frac{g_{i, N-1}\left(P_{i, N-1}\right)}{f_{i, N-1}\left(P_{i, N-1}\right)}\right]
\end{aligned}
$$

By inductive reasoning the value function of the type $i$ buyers at $n$ can be expressed as

$$
J_{i, n}^{*}\left(V_{i, n}\right)=-\frac{1}{a_{i}} \exp \left(-a_{i} R_{n} V_{i, n}\right) \Theta_{i, n}
$$

where $\Theta_{i, n}$ is independent of $V_{i, n}$ and $\mathcal{F}_{n}$-measurable. From (60) $\Theta_{i, n}$ can be induced as

$$
\begin{aligned}
\Theta_{i, n}= & \exp \left(a_{i} R_{n} \alpha_{i, n+1}^{*} W_{n}^{*}-E_{n}^{\mathbb{Q}}\left[\frac{g_{i, n+1}\left(P_{i, n+1}\right)}{f_{i, n+1}\left(P_{i, n+1}\right)}\right]\right. \\
& \left.+E_{n}^{\mathbb{Q}}\left[\ln E_{n}\left[\exp \left(-a_{i} R_{n+1} \alpha_{i, n+1}^{*} W_{n+1}\right) \Theta_{i, n+1} \mid P_{i, n+1}\right]\right]\right) \\
& \times E_{n}\left[\frac{\exp \left(-a_{i} R_{n+1} \alpha_{i, n+1}^{*} W_{n+1}\right) \Theta_{i, n+1}}{E_{n}\left[\exp \left(-a_{i} R_{n+1} \alpha_{i, n+1}^{*} W_{n+1}\right) \Theta_{i, n+1} \mid P_{i, n+1}\right]}\right. \\
& \left.\times \frac{g_{i, n+1}\left(P_{i, n+1}\right)}{f_{i, n+1}\left(P_{i, n+1}\right)}\right] \\
\forall n= & 0,1, \ldots, N-2
\end{aligned}
$$

In a similar manner we obtain the value function of type $j$ buyers at time $n$ as:

$$
J_{j, n}^{*}\left(V_{j, n}\right)=-\frac{1}{a_{j}} \exp \left(-a_{j} R_{n} V_{j, n}\right) \Theta_{j, n}
$$

where the $\mathcal{F}_{n}$-measurable random variable $\Theta_{j, n}$ can be induced as

$$
\Theta_{j, n}=\exp \left(a_{j} R_{n} \alpha_{j, n+1}^{*} W_{n}^{*}\right)
$$




$$
\times E_{n}\left[\exp \left(-a_{j} R_{n+1} \alpha_{j, n+1}^{*} W_{n+1}\right) \Theta_{j, n+1}\right] \quad \forall n=0,1, \ldots, N-2
$$

Finally the issuer's value function at time n can be derived as

$$
J_{m, n}^{*}\left(V_{m, n}\right)=-\frac{1}{a_{m}} \exp \left(-a_{m} R_{n} V_{m, n}\right) \quad \forall n=0,1, \ldots, N-2
$$

\section{Numerical example}

In this section we present a numerical example of our multi-period equilibrium pricing model. For simplicity we assume a two-period planning horizon and price a plainvanilla weather call option with a strike of $70^{\circ} \mathrm{F}$. The underlying weather index is one day average temperature. However, the pricing model can be easily extended to Cooling Degree Days (CDD)/Heating Degree Days (HDD) if we specify the stochastic processes of temperature during the contract period. In our economy there are 3 market participants; type $i$ buyer which has a liquid commodity derivatives market, type $j$ buyer which does not, and the issuer of the weather call option. All commodity prices and demand of the buyers are assumed to be positively correlated with temperature. In addition the temperature process follows Brownian motion with a drift term because after removing seasonality the normality of the temperature process is often assumed in literature. Moreover, we model the commodity price and demand of the type $i$ and $j$ buyers as geometric Brownian motions with a drift term. The correlated temperature, demand, and price processes can be defined as

$$
\begin{aligned}
& T_{N}=T_{0}+\mu_{T} N+W_{N}^{1} \\
& D_{k, N}=D_{k, 0} \exp \left(\left(\mu_{D_{k}}-\frac{1}{2} \sigma_{D_{k}}^{2}\right) N+\sigma_{D_{k}} W_{k, N}^{2}\right) \\
& P_{k, n}=P_{k, 0} \exp \left(\left(\mu_{P_{k}}-\frac{1}{2} \sigma_{P_{k}}^{2}\right) n+\sigma_{P_{k}} W_{k, n}^{3}\right) \\
& \forall k \in\{i, j\} \text { and } n \in\left\{n_{0}=0, n_{1}, \ldots, n_{N}=N\right\}
\end{aligned}
$$

where $W_{N}^{1}, W_{i, N}^{2}, W_{j, N}^{2}, W_{i, n}^{3}$, and $W_{i, n}^{3}$ are correlated Brownian motions representing the correlation among temperature, demand, and price of the type $i$ and $j$ commodities. Since we have a two-period planning horizon, Brownian motions will be discretized by combining correlated standard normal distributions and a Markovian property. In other words we observe the realization of Brownian motions at $n_{0}=0$, $n_{1}=\Delta$, and $n_{2}=2 \Delta$.

In this example we will vary the correlation of Brownian motions between demand of the type $i$ commodity and temperature from 0.2 to 0.8 . All other correlation coefficients among Brownian motions $\rho$ are fixed and listed in Table 1 which is positive semi-definite for the range of the varied correlations. In addition we assume that the real world probability measure $\mathbb{P}$ is equal to a risk-neutral probability measure $\mathbb{Q}$ in each commodity market for simplicity. This assumption has been justified in the Nordic power market by Audet et al. [3]. In our single-period equilibrium 
Table 1 Correlation $(\rho)$ matrix

\begin{tabular}{llllll}
\hline & $T_{N}$ & $D_{i, N}$ & $P_{i, N}$ & $D_{j, N}$ & $P_{j, N}$ \\
\hline$T_{N}$ & 1 & vary & 0.3 & 0.6 & 0.3 \\
$D_{i, N}$ & & 1 & 0.5 & 0.15 & 0.1 \\
$P_{i, N}$ & & & 1 & 0.1 & 0.1 \\
$D_{j, N}$ & & & & 1 & 0.5 \\
$P_{j, N}$ & & & & & 1 \\
\hline
\end{tabular}

Table 2 Parameters

\begin{tabular}{ll}
\hline & Parameters \\
\hline Temperature & $T(0)=65, \mu_{T}=1, \sigma_{T}=5$ \\
Type $i \& j$ & $\mu_{D_{k}}=\mu_{P_{k}}=0.1, \sigma_{D_{k}}=0.3, \sigma_{P_{k}}=0.1, P_{k}^{R}=11$ \\
Risk aver. & 0.1 \\
$\Delta$ & 0.5 \\
\hline
\end{tabular}

pricing formula (12) of type $i$ buyers we need to calculate conditional expectation $E_{N-1}\left[\exp \left(-a_{i}\left(I_{i}+\alpha_{N} W_{N}\right)\right) \mid P_{i, N}\right]$ and this can be obtained from the following conditional probability density functions.

$$
\begin{gathered}
\ln D_{i, N} \mid P_{i, N} \sim N\left(\mu_{1}+\rho_{D_{i, N}, P_{i, N}}\left(\ln \left(P_{i, N}\right)-\mu_{2}\right) \frac{\sigma_{D_{i}}}{\sigma_{P_{i}}},\left(1-\rho_{D_{i, N}, P_{i, N}}^{2}\right) \sigma_{D_{i}}^{2} n_{1}\right) \\
T_{N} \mid P_{i, N} \sim N\left(\mu_{3}+\rho_{T, P_{i, N}}\left(\ln \left(P_{i, N}\right)-\mu_{2}\right) \frac{\sigma_{T}}{\sigma_{P_{i}}},\left(1-\rho_{D_{i, N}, P_{i, N}}^{2}\right) \sigma_{T}^{2} n_{1}\right)
\end{gathered}
$$

where $\mu_{1}, \mu_{2}$, and $\mu_{3}$ have the form of

$$
\begin{aligned}
& \mu_{1}=\ln \left(D_{i, 0}\right)+\left(\mu_{D_{i}}-\frac{1}{2} \sigma_{D_{i}}^{2}\right)(2 \Delta) \\
& \mu_{2}=\ln \left(P_{i, n_{1}}\right)+\left(\mu_{P_{i}}-\frac{1}{2} \sigma_{P_{i}}^{2}\right) \Delta \\
& \mu_{3}=T_{0}+\mu_{T}(2 \Delta)
\end{aligned}
$$

Other parameters in this numerical example are specified in Table 2.

Figure 1 illustrates the optimal choices of the weather call option for type $i$ and $j$ buyers and the sum of the two optimal quantities representing aggregate demand or supply quantities. In both figures we can see that the type $i$ buyer shorts and the type $j$ buyer longs. Recall the assumption that the type $i$ buyer can construct the commodity derivatives portfolio with continuous strike prices. These infinitely many commodity derivatives have more flexibility to hedge risks than the weather call option which is just a small part of available derivatives. Therefore, type $i$ buyer shorts the weather 


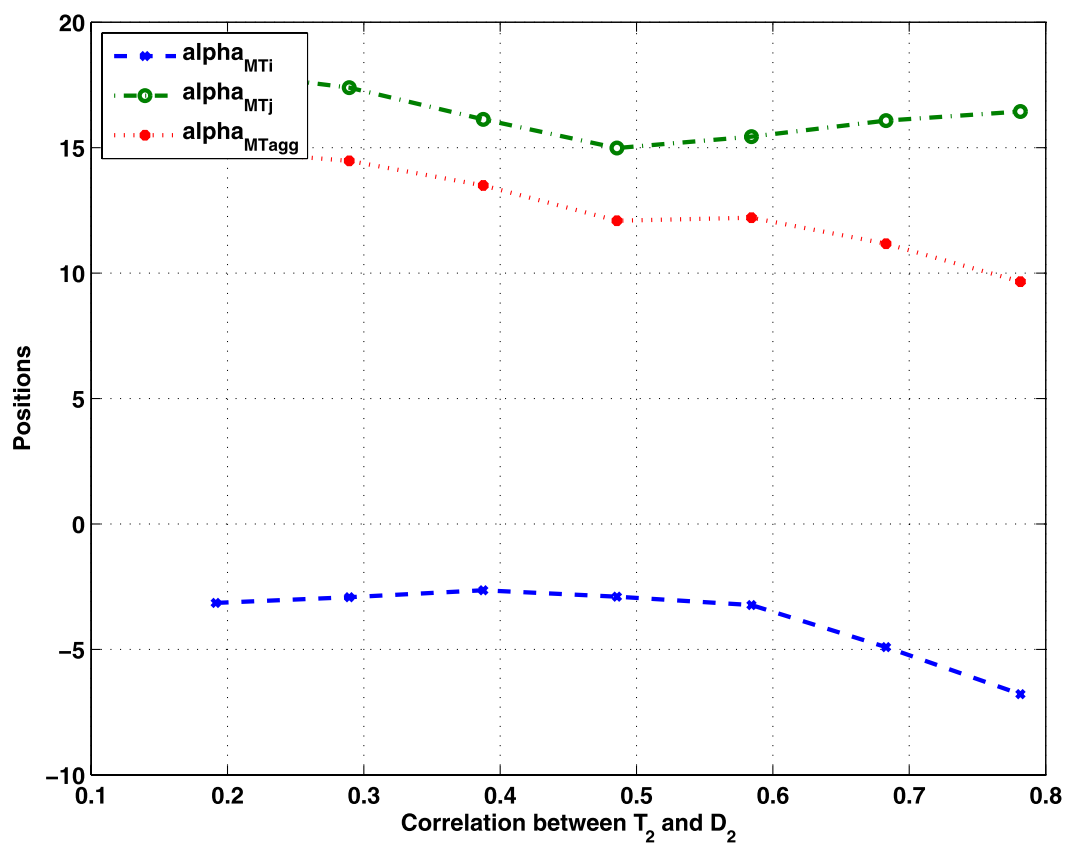

(a) Optimal Choices of Two-period

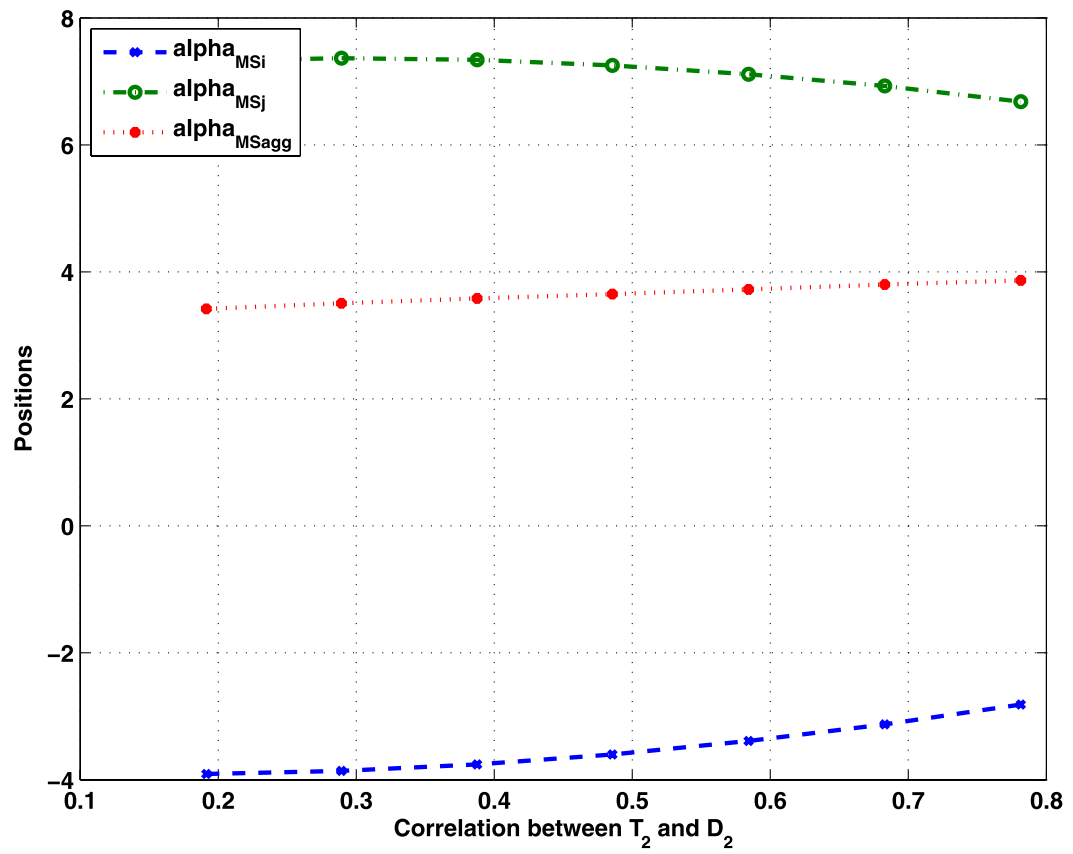

(b) Optimal Choices of Single-period

Fig. 1 Optimal choices of two \& single-period 


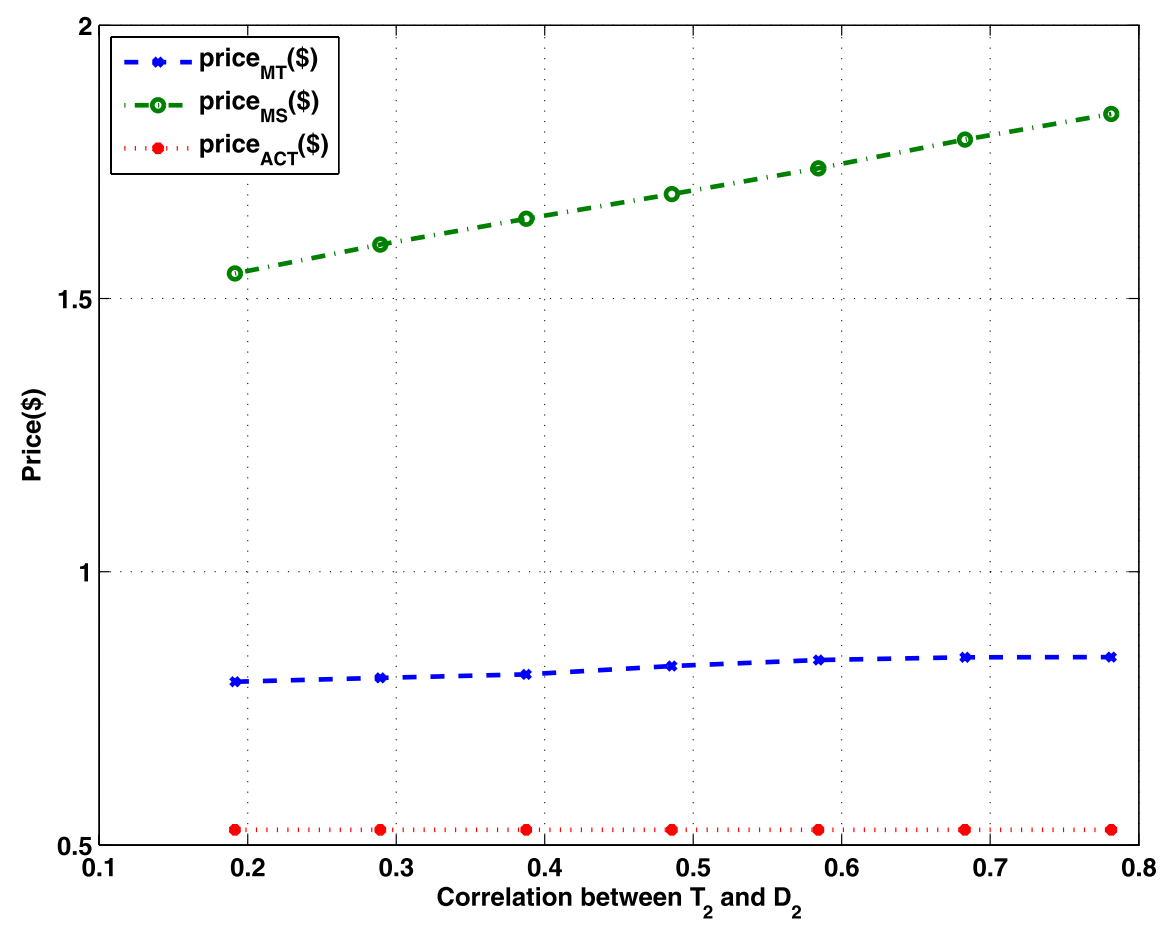

Fig. 2 Equilibrium price of two \& single-period

call option and invests more in commodity derivatives. This interpretation is also verified in Fig. 5. The variance reduction of the portfolio with commodity derivatives and the weather call option is almost the same as the portfolio with commodity derivatives only, which means that the weather call options have relatively small effect on the portfolio of type $i$ buyer.

Figure 2 shows the equilibrium prices of the weather call option in the two-period, single-period, and the actuarial cases. Here the actuarial price is defined as the discounted expectation of the weather call option payoff under the real world probability measure $\mathbb{P}$. The actuarial price graph is flat because the temperature process is independent of the correlation coefficient $\rho_{T_{2}, D_{i, 2}}$. In this figure we can see that the price is lowest under actuarial pricing, higher for the two-period case and the highest under the single period case. The positive difference between the single or two-period equilibrium price and the actuarial price represents the risk premium due to buyers' risk-aversion.

The certainty equivalents (CE) of type $i$ and $j$ buyers for the single and two-period case are shown in Fig. 3. The certainty equivalent for the two-period case is always higher for both types of buyers. The difference in certainty equivalents between the single and two-period case captures the value of the additional trading opportunity at time 1.

Figure 4 shows the optimal payoff functions of the commodity portfolios at time 0 and 1 when the correlation coefficient $\rho_{T_{2}, D_{i, 2}}$ is equal to 0.80 . Figure $4(\mathrm{a})$ exhibits 


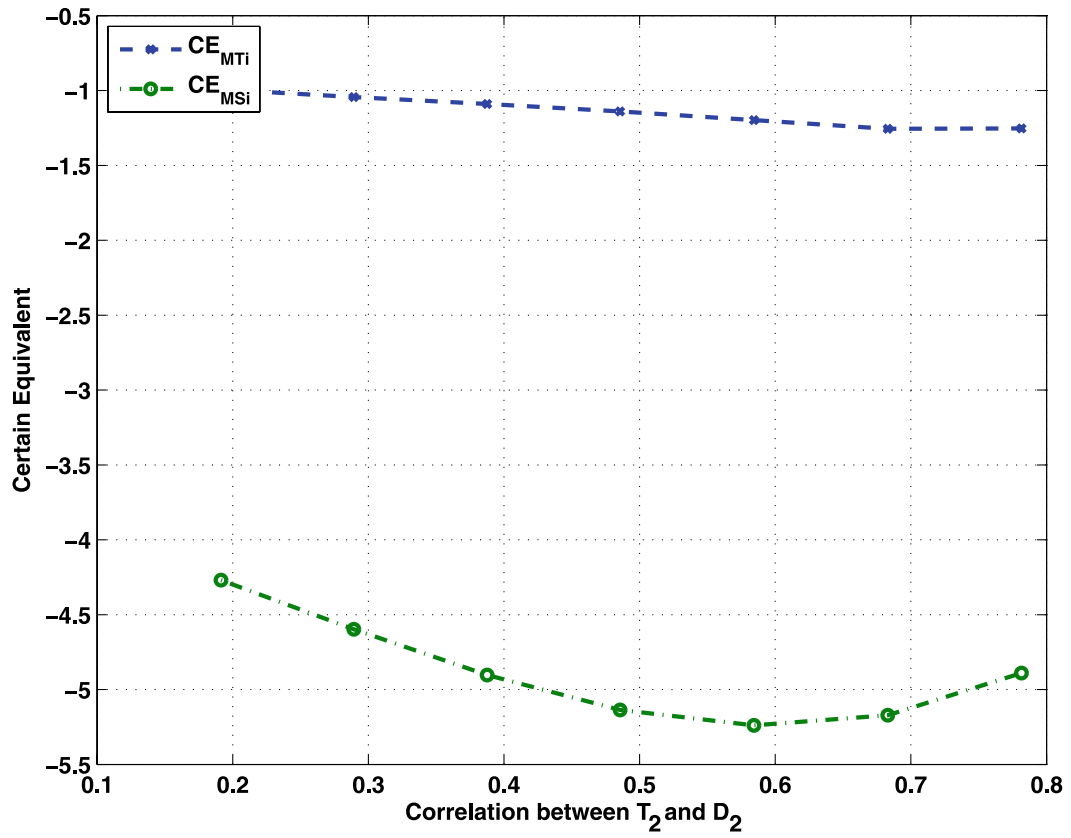

(a) CE of Two \& Single-period of type $i$ buyer

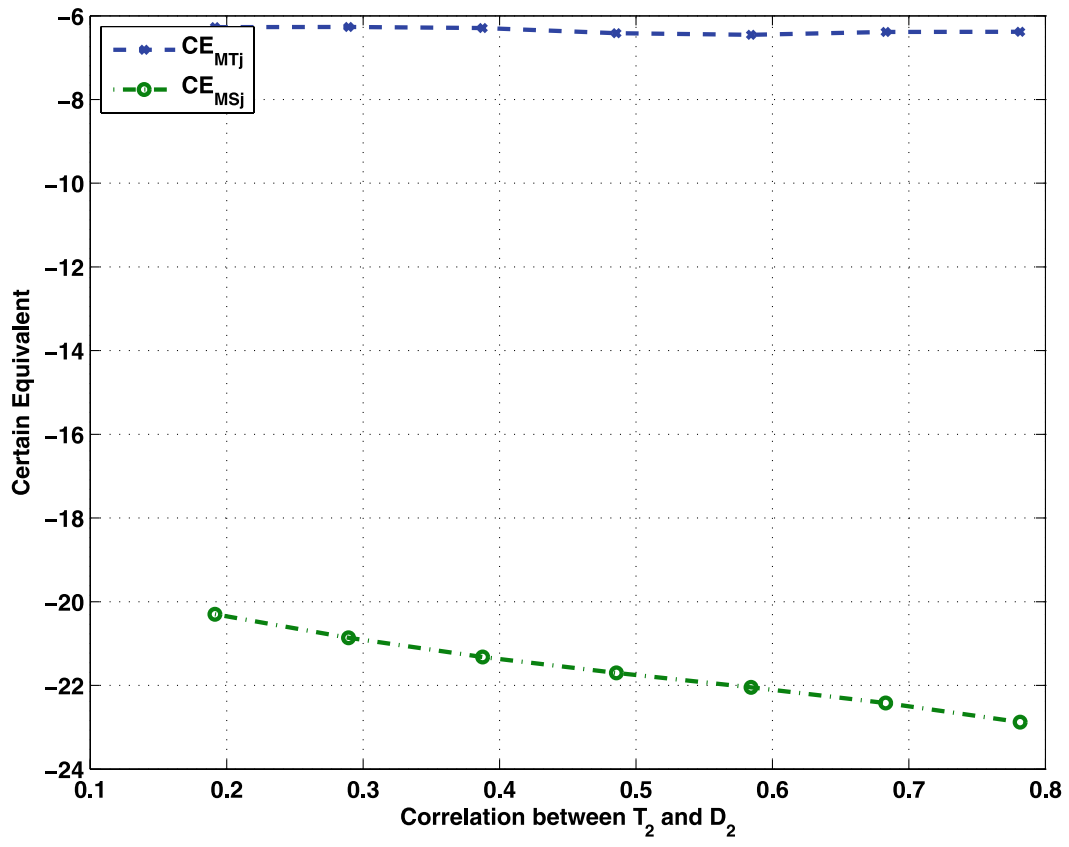

(b) CE of Two \& Single Period of type $j$ buyer

Fig. 3 Certainty equivalents (CE) 


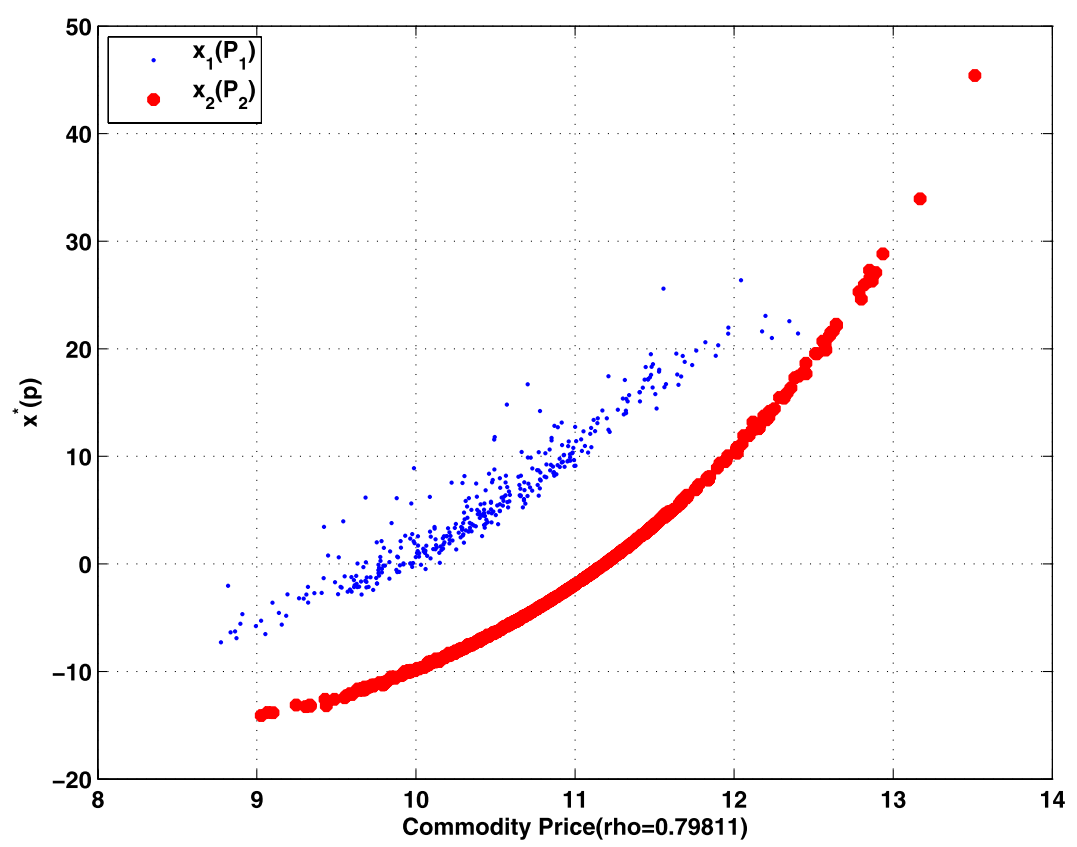

(a) With Weather Call Option

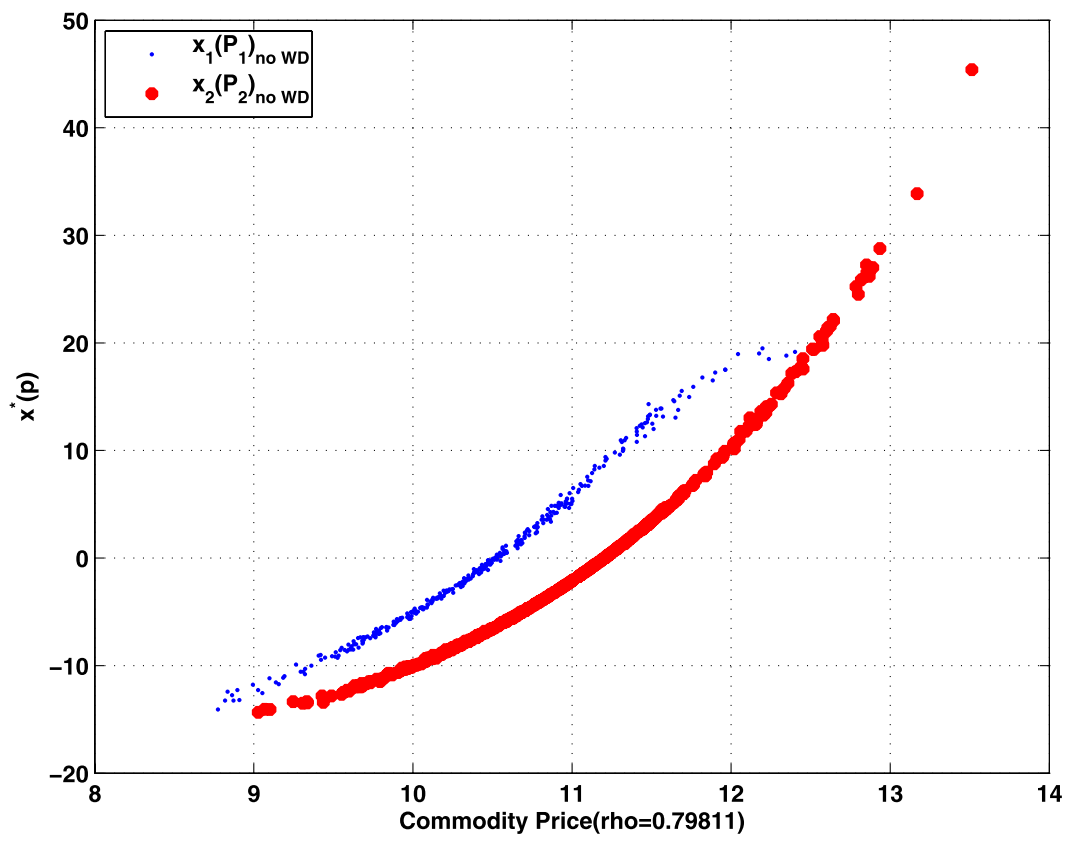

(b) Without Weather Call Option

Fig. 4 Optimal payoff functions $\left(\rho_{T_{2}, D_{i, 2}}=0.80\right)$ 
the optimal payoff of the portfolio with commodity derivatives and the weather call option. In the case with only commodity derivatives, the optimal payoff function has the form of Fig. 4(b).

Figure 5(a) illustrates the probability density functions (p.d.f.) of terminal wealth for the type $i$ buyer in three cases. If the type i buyer is not hedged and exposed to all price and volumetric risks, the p.d.f. of terminal wealth is widely spread, i.e. has large variance or risk. However, if the commodity derivatives are included in the portfolio then the risk is greatly reduced. Compared to the portfolio with commodity derivatives only, the portfolio with commodity derivatives and the weather call option shows very similar probability density functions. This can be explained by the fact that our portfolio of commodity derivatives includes a continuum of strikes whereas the weather call option is just one derivative. However, in Fig. 5(b) type $j$ buyer is better off in terms of risk reduction when the weather call option is purchased because the variance is reduced about $3 \%$ by including the weather derivative. Therefore, we conclude that the weather call option plays a relatively important role in the portfolio of type $j$ buyer but is insignificant for type i buyer who can use commodity derivatives to hedge both price and volumetric risk.

\section{Conclusion}

Many weather-sensitive industries such as energy, insurance, agriculture, and leisure are exposed to price and volumetric risks coming from the stochastic aspect of cost (or wholesale price) and demand in their profit functions. In addition these price and volumetric risks are all correlated with weather. Commodity derivatives can mitigate price risk but volumetric risk typically associated with weather changes can only be partially hedged via commodity derivatives. Therefore, new financial instruments are needed and weather derivatives represent an effective means for hedging volume risk because demand is strongly correlated with weather. However, pricing weather derivative is not a trivial task because of market incompleteness and it becomes even more challenging in a dynamic setting.

In this paper we investigate a multi-period equilibrium pricing model for weather derivative pricing within a framework of a stylized economy. Three types of market participants are considered, buyers with and without a liquid commodity derivatives market and an issuer. All market participants are assumed to maximize expected utility of terminal wealth subject to self-financing trading constraints and are able to rebalance their portfolios in each period. We use dynamic programming and indifference pricing to recursively derive the supply and demand function for the weather derivative in each period. We then apply a market clearing condition to determine the equilibrium prices of the weather derivative in each period.

A numerical example employing Monte-Carlo simulations illustrates the formation of the equilibrium prices and the optimal choices of the weather call options in a single and multi-period setting under various correlations between volumetric and weather risks. The value of multiple trading opportunities is also demonstrated. We also show how the weather derivative improves risk hedging capability by reducing variance of terminal wealth, especially in situations where commodity derivatives are not available. 


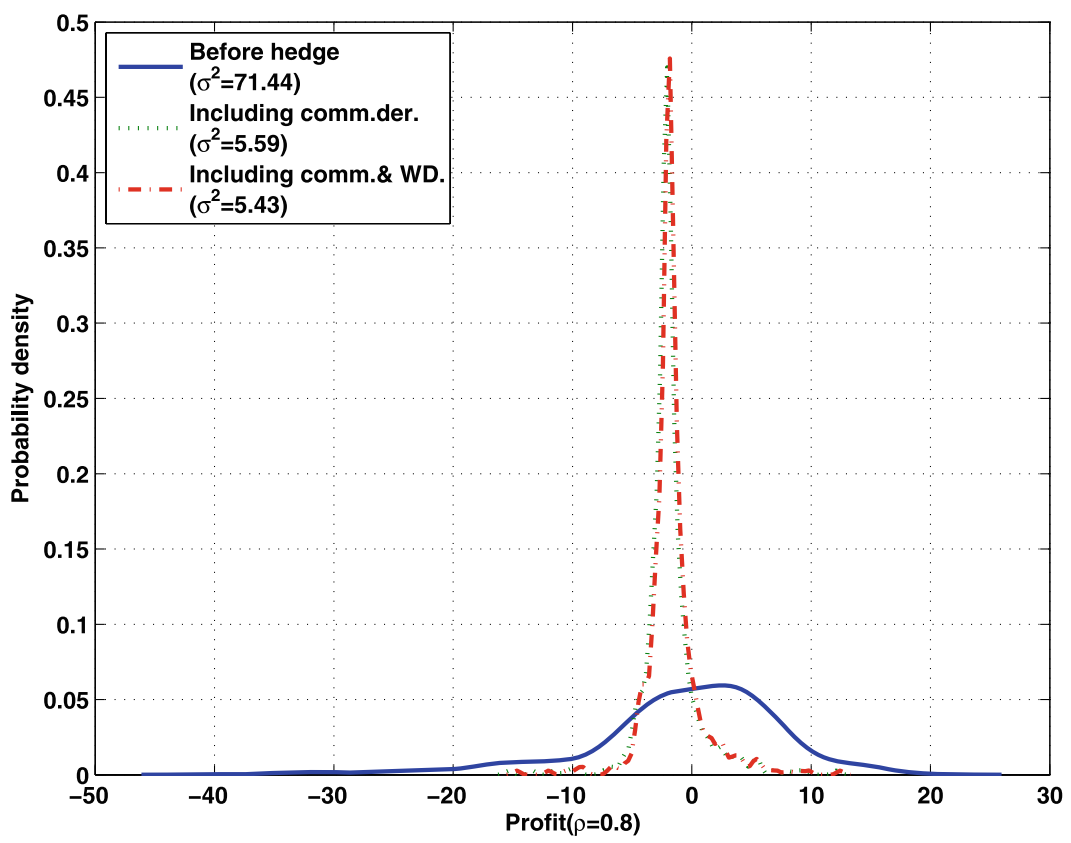

(a) Type $i$ Buyer

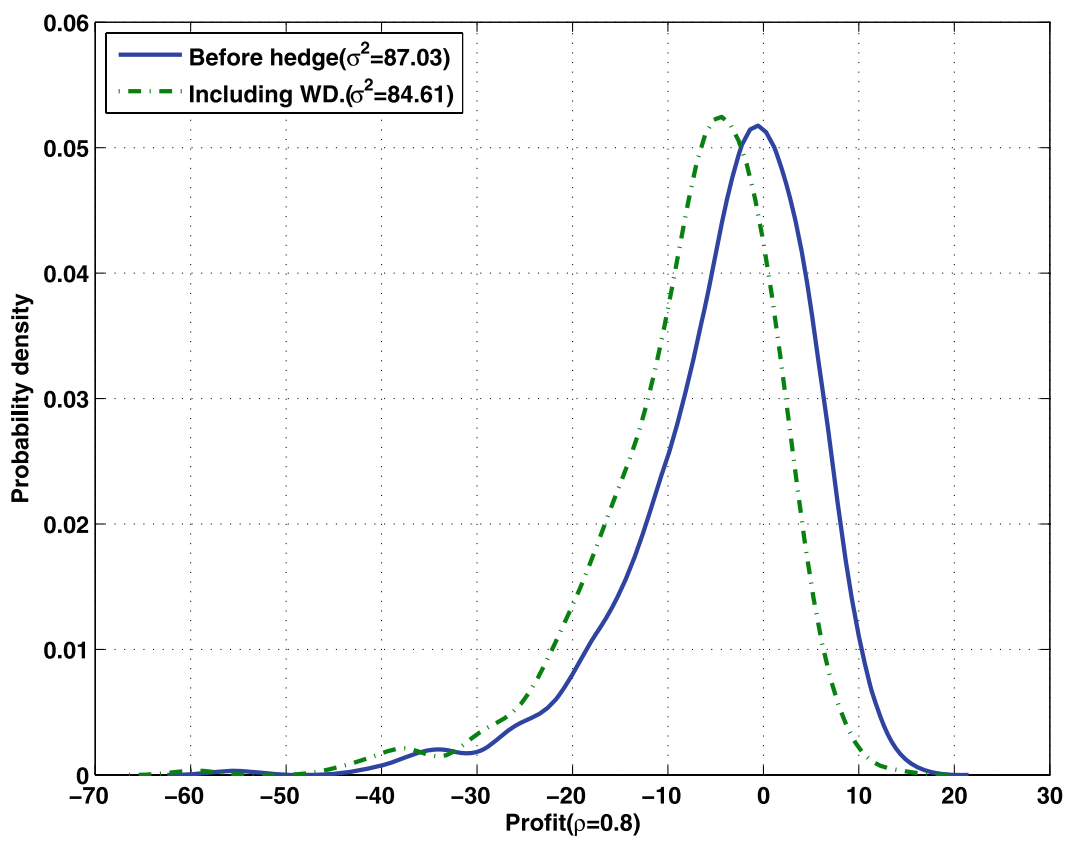

(b) Type $j$ Buyer

Fig. 5 P.D.F. of type $i$ and $j$ 's profit function $\left(\rho_{1}=0.80\right)$ 
Open Access This article is distributed under the terms of the Creative Commons Attribution Noncommercial License which permits any noncommercial use, distribution, and reproduction in any medium, provided the original author(s) and source are credited.

\section{Appendix}

Proof of Proposition 1: the optimal $x_{i, N}\left(P_{i, N}\right)$ Let $C_{i, n}$ denote the self-financing constraint at time $n$, i.e. $E_{n}^{\mathbb{Q}}\left[\frac{x_{i, n+1}\left(P_{i, n+1}\right)}{1+r_{n}}\right]+\alpha_{i, n+1} W_{n}-V_{i, n}$. Then we can form the Lagrangian function as

$$
\begin{aligned}
L_{i, N-1}= & E_{N-1}\left[U_{i}\left(\Pi_{i, N}\right)\right]-\lambda_{i, N} C_{i, N-1} \\
= & \int_{-\infty}^{\infty} E_{N-1}\left[U_{i}\left(\Pi_{i, N}\right) \mid P_{i, N}=p\right] f_{i, N}(p) d p \\
& -\frac{\lambda_{i, N}}{1+r_{N-1}}\left(\int_{-\infty}^{\infty} x_{i, N}(p) g_{i, N}(p) d p+\alpha_{i, N} W_{N-1}-V_{i, N-1}\right)
\end{aligned}
$$

where $f_{i, N}(p)$ is a marginal probability density function of the type i commodity spot price $P_{i, N}$ under the real probability measure $\mathbb{P}$ and $g_{i, N}(p)$ is a risk-neutral probability density function of $P_{i, N}$. Because the commodity market is incomplete there may exist infinitely many risk-neutral probability measures and we assume that a risk-neutral probability measure is properly chosen under some criterion, for example, minimum distance equivalent martingale measure. The ratio $\frac{g_{i, N}(p)}{f_{i, N}(p)}$ is a RadonNicodym derivative in the type $i$ commodity market and satisfies $E\left[\frac{g_{i, N}(p)}{f_{i, N}(p)}\right]=1$. The partial derivative with respect to $x_{i, N}(p)$ requires the Euler equation for the functional derivatives because the decision variable $x_{i, N}\left(P_{i, N}\right)$ is a deterministic function of the random variable $P_{i, N}$. The value function at $N-1$ can be expressed using the Lagrange multiplier as

$$
\begin{aligned}
J\left(V_{i, N-1}-\alpha_{i, N} W_{N-1}, \alpha_{i, N}\right) & =\max _{\left\{x_{i, N}\left(P_{N}\right), \lambda_{i, N}\right\}} E_{N-1}\left[J\left(V_{i, N}\right)\right]-\lambda_{i, N} C_{i, N-1} \\
& =\max _{\left\{x_{i, N}\left(P_{N}\right), \lambda_{i, N}\right\}} L_{i, N-1}
\end{aligned}
$$

Taking the partial derivative with respect to $x_{i, N}(p)$ based on calculus of variation and $\lambda_{i, N}$ gives us the first order necessary conditions as

$$
\begin{aligned}
& \frac{\partial L_{i, N-1}}{\partial x_{i, N}(p)}=E_{N-1}\left[U_{i}^{\prime}\left(\Pi_{i, N}\right) \frac{\partial \Pi_{i, N}}{\partial x_{i, N}(p)} \mid p\right] f_{i, N}(p)-\lambda_{i, N} \frac{g_{i, N}(p)}{1+r_{N-1}}=0 \\
& \frac{\partial L_{i, N-1}}{\partial \lambda_{i, N}}=V_{i, N-1}-\left(E_{N-1}^{\mathbb{Q}}\left[\frac{x_{i, N}\left(P_{i, N}\right)}{1+r_{N-1}}\right]+\alpha_{i, N} W_{N-1}\right)=0 \\
& \quad \forall i=1,2 \ldots, u
\end{aligned}
$$

Note that the first order conditions are sufficient for the optimality because the problem is a convex optimization problem. Moreover, under the assumption $E_{0}\left[\left|U_{i}(\cdot)\right|\right]<$ $\infty$ the partial derivative and the expectation operator are interchangeable. 
From (72) and (73) the optimality conditions of the Lagrangian relaxation problem under the exponential utility function are

$$
\begin{aligned}
\frac{\partial L_{i, N-1}}{\partial x_{i, N}(p)}= & f_{i, N}(p)\left(E_{N-1}\left[\exp \left(-a_{i}\left(I_{i, N}+x_{i, N}(p)+\alpha_{i, N} W_{N}\right)\right) \mid p\right]\right) \\
& -\lambda_{i, N} \frac{g_{i, N}(p)}{1+r_{N-1}}=0 \\
\frac{\partial L_{i, N-1}}{\partial \lambda_{i, N}}= & V_{i, N-1}-\left(E_{N-1}^{\mathbb{Q}}\left[\frac{x_{i, N}\left(P_{i, N}\right)}{1+r_{N-1}}\right]+\alpha_{i, N} W_{N-1}\right)=0
\end{aligned}
$$

Given $p, x_{i, N}(p)$ can be taken out of the expectation operator and then (74) can be simplified as

$$
\begin{aligned}
x_{i, N}(p)= & \frac{1}{a_{i}}\left(\ln E_{N-1}\left[\exp \left(-a_{i}\left(I_{i}+\alpha_{i, N} W_{N}\right)\right) \mid p\right]-\ln \frac{\lambda_{i, N}}{1+r_{N-1}}\right. \\
& \left.-\ln \frac{g_{i, N}(p)}{f_{i, N}(p)}\right)
\end{aligned}
$$

Because the above equation holds for all $\mathrm{p}$ we can substitute $P_{i, N}$ for $p$. Then, taking expectation on both sides of (76) under $\mathbb{Q}$ and combining with (75) imply

$$
\begin{aligned}
E_{N-1}^{\mathbb{Q}}\left[x_{i, N}\left(P_{i, N}\right)\right]= & \frac{1}{a_{i}}\left(E_{N-1}^{\mathbb{Q}}\left[\ln E_{N-1}\left[\exp \left(-a_{i}\left(I_{i}+\alpha_{i, N} W_{N}\right)\right) \mid P_{i, N}\right]\right]\right. \\
& \left.-\ln \frac{\lambda_{i, N}}{1+r_{N-1}}-E_{N-1}^{\mathbb{Q}}\left[\ln \frac{g_{i, N}\left(P_{i, N}\right)}{f_{i, N}\left(P_{i, N}\right)}\right]\right) \\
= & \left(1+r_{N-1}\right)\left(V_{i, N-1}-\alpha_{i, N} W_{N-1}\right)
\end{aligned}
$$

After simplifying we have

$$
\begin{aligned}
\ln \frac{\lambda_{i, N}}{1+r_{N-1}}= & E_{N-1}^{\mathbb{Q}}\left[\ln E_{N-1}\left[\exp \left(-a_{i}\left(I_{i}+\alpha_{i, N} W_{N}\right)\right) \mid P_{i, N}\right]\right] \\
& -E_{N-1}^{\mathbb{Q}}\left[\ln \frac{g_{i, N}\left(P_{i, N}\right)}{f_{i, N}\left(P_{i, N}\right)}\right] \\
& -a_{i}\left(1+r_{N-1}\right)\left(V_{i, N-1}-\alpha_{i, N} W_{N-1}\right)
\end{aligned}
$$

Plugging (78) into (76) we get the resulting optimal payoff function.

\section{References}

1. Alaton, P., Djehiche, B., Stillberger, D.: On modelling and pricing weather derivatives. Appl. Math. Finance 9, 1-20 (2002)

2. Ankirchner, S., Imkeller, P., Popier, A.: Optimal cross hedging of insurance derivatives. Stoch. Anal. Appl. 26, 679-709 (2008) 
3. Audet, N., Heiskanen, P., Keppo, J., Vehvilainen, I.: Modeling electricity forward curve dynamics in the Nordic market. In: Bunn, D.W. (ed.): Modelling Prices in Competitive Electricity Markets. Wiley Series in Financial Economics, pp. 251-265. Wiley, New York (2004)

4. Benth, F.: Arbitrage-free pricing of weather derivatives based on fractional Brownian motion. Appl. Math. Finance 10, 303-324 (2003)

5. Black, F., Scholes, M.: The pricing of options and corporate liabilities. J. Polit. Econ. 81, 637-655 (1973)

6. Brockett, P.L., Wang, M.: Portfolio effects and valuation of weather derivatives. Financ. Rev. 41 (2006)

7. Brody, D., Syroka, J., Zervos, M.: Dynamic pricing of weather derivatives. Quant. Finance 2, 189-198 (2002)

8. Cao, M., Wei, J.: Pricing weather derivative: an equilibrium approach. J. Futures Mark. 24, 1065-1089 (2004)

9. Carr, P., Madan, D.: Optimal positioning in derivative securities. Quant. Finance 1, 19-37 (2001)

10. Chaumont, S., Imkeller, P., Muller, M., Horst, U.: A simple model for trading climate risk. Q. J. Econ. Res. 74 (2005)

11. Davis, M.: Pricing weather derivatives by marginal value. Quant. Finance 1, 305-308 (2001)

12. Frittelli, M.: The minimal entropy martingale measure and the valuation problem in incomplete markets. Math. Finance 10, 39-52 (2000)

13. Goll, T., Ruschendorf, L.: Minimal distance martingale measures and optimal portfolios consistent with observed market prices. Finance Stoch. 5, 557-581 (2001)

14. Hamisultane, H.: Extracting information from the market to price the weather derivatives. ICFAI J. Deriv. Mark. 4, 17-46 (2007)

15. Heath, D., Jarrow, R., Morton, A.: Bond pricing and the term structure of interest rates: a new methodology for contingent claim valuation. Econometrica 66, 77-105 (1992)

16. Jewson, S., Brix, A.: Weather Derivative Valuation. Cambridge (2005)

17. Jewson, S., Caballero, R.: Seasonality in the statistics of surface air temperature and the pricing of weather derivatives. Meteorol. Appl. 10, 367-376 (2003)

18. Jouini, E.: Arbitrage and control problems in finance: a presentation. J. Math. Econ. 35, 167-183 (2001)

19. Kroll, Y., Levy, H., Markowitz, H.M.: Mean-variance versus direct utility maximization. J. Finance 39(1), 47-61 (1984)

20. Lee, Y., Oren, S.S.: An equilibrium pricing model for weather derivatives in a multi-commodity setting. Energy Econ. 31, 702-713 (2009)

21. Li, X., Sailor, D.J.: Electricity use sensitivity and climate and climate change. World Resour. Rev. 3, 334-346 (1995)

22. Lucas, R.E.: Asset prices in an exchange economy. Econometrica 46, 1429-1445 (1978)

23. Merton, R.C.: Theory of rational option pricing. Bell J. Econ. Manag. Sci. 4, 141-183 (1973)

24. Platen, E., West, J.: A fair pricing approach to weather derivatives. Asia-Pac. Financ. Mark. 11, 23-53 (2004)

25. Richards, T.J., Manfredo, M.R., Sanders, D.R.: Pricing weather derivatives. Am. J. Agric. Econ. 86 (2004)

26. Samuelson, P.A.: Lifetime portfolio selection by dynamic stochastic programming. Rev. Econ. Stat. 51, 239-246 (1969)

27. Schweizer, M.: Approximation pricing and the variance-optimal martingale measure. Ann. Probab. 24, 206-236 (1996)

28. Staum, J.: Fundamental theorems of asset pricing for good deal bounds. Math. Finance 14(2), 141-161 (2004)

29. Staum, J.: Incomplete Market. Elsevier, Amsterdam (2008), Chap. 12, pp. 511-563

30. Yamada, Y.: Valuation and hedging of weather derivatives on monthly average temperature. J. Risk 10 (2007)

31. Yoo, S.: Weather derivatives and seasonal forecast. Asia-Pac. J. Financ. Stud. 213-246 (2004) 